No. 21-9

\title{
Rising Geographic Disparities in US Mortality
}

\author{
Benjamin K. Couillard, Christopher L. Foote, Kavish Gandhi, \\ Ellen Meara, and Jonathan Skinner
}

\begin{abstract}
:
The 21st century has been a period of rising inequality in both income and health. In this study, we find that geographic inequality in mortality for midlife Americans increased by about 70 percent from 1992 to 2016. This was not simply because states such as New York or California benefited from having a high fraction of college-educated residents who enjoyed the largest health gains during the last several decades. Nor was higher dispersion in mortality caused entirely by the increasing importance of "deaths of despair," or by rising spatial income inequality during the same period. Instead, over time, state-level mortality has become increasingly correlated with state-level income; in 1992 income explained only 3 percent of mortality inequality, but by 2016 state-level income explained 58 percent. These mortality patterns are consistent with the view that high-income states in 1992 were better able to enact public health strategies and adopt behaviors that, over the next quarter-century, resulted in pronounced relative declines in mortality. The substantial longevity gains in high-income states led to greater cross-state inequality in mortality.
\end{abstract}

JEL Classifications: I11, I12, I14, I15, I18

Keywords: mortality, health, health policy

Benjamin K. Couillard (bcouillard22@gmail.com) is a PhD student in economics at the University of Toronto. Christopher L. Foote (chris.foote@bos.frb.org) is a senior economist and policy advisor at the Federal Reserve Bank of Boston. Kavish Gandhi (kavish.gandhi@bos.frb.org) is a senior research assistant at the Boston Fed. Ellen Meara (emeara@hsph.harvard.edu) is a professor of health economics and policy at Harvard University's T.H. Chan School of Public Health. Jonathan Skinner (jon.skinner@dartmouth.edu) is a research professor in economics at Dartmouth College. Meara and Skinner are also research associates at the National Bureau of Economic Research.

The authors are grateful to Anne Case, Angus Deaton, Amy Finkelstein, Victor Fuchs, Matt Gentzkow, Eric Hurst, Heidi Williams, and especially Timothy Taylor for helpful comments and suggestions. Meara and Skinner are grateful for financial support from the National Institute on Aging (AG060104-01).

This paper was prepared for the Journal of Economic Perspectives.

The views expressed herein are those of the authors and do not indicate concurrence by the Federal Reserve Bank of Boston, the principals of the Board of Governors, or the Federal Reserve System. This paper is available on the Boston Fed website at https://www.bostonfed.org/publications/research-department-working-paper.aspx. 
Until recently, Americans could expect to live longer than their parents. Overall US life expectancy rose steadily from the 1960s through the early 2000s. As Figure 1 shows, the 1.5-year drop in life expectancy in 2020 signaled a sharp reversal; indeed it was the largest decline since World War II. But even before the COVID-19 pandemic, US life expectancy was essentially flat for about a decade and even declined slightly after 2014. Public health officials and health researchers have become increasingly concerned about this plateau, and as they study it, another important fact has emerged: disparities in mortality have become increasingly apparent among different groups in the population.

Much of the recent research on life expectancy focuses on particularly worrisome mortality trends for persons at midlife, defined as ages 25 through 64. A recent report from the National Academies of Sciences, Engineering, and Medicine (2021) reviews this work and links high and rising midlife mortality rates to two main factors. First, rapid progress that had been made in reducing mortality from some major causes, most notably heart disease, stalled after 2010. Second, deaths from suicide, drug poisoning, and alcohol-induced causes have risen sharply. These deaths, often labelled "deaths of despair," have been the focus of extensive research by Anne Case and Angus Deaton (2015; 2017; 2020). Regarding mortality disparities, the National Academies report notes large and widening mortality differences based on race, ethnicity, economic status, and geography. For example, recent increases in mortality among Black and Hispanic persons have undone years of progress in addressing high mortality rates among these groups (Harris, Woolf, and Gaskin 2021).

In this paper, we document and analyze rising geographic disparities in health, focusing on the state level. Vierboom, Preston, and Hendi (2019) highlight growing local inequality in longevity after 2000; coastal cities gained while rural Appalachia and the South lagged behind. Woolf and Schoomaker (2019) document divergence in life expectancy among US states beginning about a decade earlier. Figure 1 shows that the coefficient of variation of state life-expectancy rates (defined as the standard deviation of these rates divided by the mean) began to rise long before average US life expectancy flattened out.

Figure 2 shows that dispersion in state-level life expectancy has been generated by increased dispersion in mortality throughout the age distribution. For the most part, average group-specific mortality rates have trended downward for each of the four age groups depicted (0 to 4, 5 to 24,25 to 64, and 65-plus). The stalling of US life expectancy around 2010 resulted from a flattening out of mortality (or outright increases in mortality) for the three age groups younger than 65. But in each of the four groups, dispersion has generally trended higher during the last several decades, especially for the three youngest groups. Although recent trends in race-specific mortality rates contribute to geographic dispersion in mortality, racial patterns alone do not explain why mortality experiences have become more unequal at the state level. In the appendix, we show that state-level dispersion has been rising among 
Black and white non-Hispanic populations separately, while a declining dispersion trend for the Hispanic population has recently flattened out.

What are the most important drivers of mortality divergence across states? One explanation is that geographic disparities are driven by differences in education levels and labor market prospects (Meara, Richards, and Cutler 2008; Case and Deaton 2015, 2017, 2020). In this view, states with relatively large or quickly growing college-educated populations shares experienced large gains in life expectancy, because recent health gains have been concentrated among Americans with college degrees. As the mortality "penalty" associated with a non-college education grew over time, states with smaller college-educated populations lagged behind.

A second and possibly related explanation is that greater dispersion in state-level mortality rates has been driven by rising spatial inequality in income. Income is unevenly distributed across the United States, and after converging for most of the 20th century, regions of the country are now growing apart economically (Ganong and Shoag 2017; Gaubert et al. 2021). Chetty et al. (2016) document a strong association between income and mortality in the United States. However, much less is known about the influence of longer-term swings over a quarter-century in income, or about how changing economic circumstances affect common causes of deaths, such as heart disease and cancer.

A third possibility is that the widening divergence in mortality stems from a portmanteau of "place" effects that are independent of state-level income. We think of these effects as capturing both the health behaviors of individuals who live in a place and the evolving features of the region's overall health environment. Much of the earlier literature on regional economic conditions and mortality focuses on deaths of despair, comparing changes in these deaths to economic shocks over relatively short periods of time (Autor, Dorn, and Hanson 2019; Pierce and Schott 2020; Charles, Hurst, and Schwartz 2018; Ruhm 2017; Hollingsworth, Ruhm, and Simon 2017; Ruhm 2019). In contrast to these short-run mechanisms, health disparities across states may arise from long-run changes in state policies or health "investments" that gradually enhance health and longevity (Montez and Berkman 2014; Montez et al. 2019). Examples of long-run health investments include anti-smoking policies, expansions of Medicaid, income support, and norms around health behaviors.

We use data on mortality, income, health behavior, and health-care quality to test these alternative hypotheses for explaining the growth in state-level disparities. Like the National Academies report and the work of Case and Deaton, we focus on mortality at midlife. We find that national trends in educational attainment and a rising national correlation between education and mortality ultimately explain little of the increasing importance of place in determining mortality. We do not find evidence that states with the most rapid income growth experienced the most rapid mortality decline. Instead, states with relatively 
high income levels over the past several decades have experienced the largest improvements in midlife mortality. Although deaths of despair have contributed to the plateau in US life expectancy, even after their recent growth they account for only about one-sixth of all midlife deaths, and we show that midlife disparities are driven largely by other causes of death. Finally, reviewing the growing literature on "place" and health, we argue that the most promising explanation for our findings involves efforts by high-income states to adopt specific health-improving policies and behaviors since at least the early 1990s. Over time, these efforts reduced mortality in high-income states more rapidly than in low-income states, leading to widening spatial disparities in health.

\section{Education and the Rising Dispersion in State-Level Mor- tality Rates}

In a series of important papers and a recent book, Case and Deaton $(2015 ; 2017 ; 2020 ; 2021)$ document the striking differences in mortality rates for Americans with different levels of education. In considering why the spatial dispersion of midlife mortality rose during the past two decades, we first consider the well-known divergence in mortality for people with and without college degrees. Because states differ in their college-educated population shares, the growing national difference between college and non-college mortality rates would by itself generate disparity in state-level mortality, particularly if college-educated persons tended to migrate to states where college attainment was already high.

Figure 3 shows all-cause midlife mortality rates separately for 1992 and 2016 for each state, ranked from highest to lowest. The bottom line in each panel is the mortality rate for college-educated residents in each state, while the top line is for non-college-educated; overall state mortality is approximately a weighted average of these two rates, with the weights reflecting the state's share of college-educated residents. Our mortality data come from the collection of individual-level detailed mortality records maintained by the National Center for Health Statistics (NCHS). Derived from death certificates, these records include the cause (or causes) of death for each decedent, as well as demographic information such as age, sex, race, education, and place of residence. Each mortality rate, then, is the number of total deaths divided by the relevant population calculated from the Current Population Survey (CPS) and the National Cancer Institute's Surveillance, Epidemiology, and End Results Program (SEER). To account for swings in mortality that would be expected from the aging of large cohorts, such as the baby boomers, we age-adjust mortality rates to reflect the deaths that would occur given a fixed age distribution. ${ }^{1}$ Starting in 1989, the US Standard Certificate

\footnotetext{
${ }^{1}$ We received permission from NCHS to use a restricted-use version of the detailed mortality files, which include state and county of residence, because these fields are suppressed in public-use files starting in 2005.
} 
of Death includes a field for the education level of the decedent. Most states were recording education on death certificates by 1992; the coverage is generally better than 90 percent after 1990 and improves steadily over time. ${ }^{2}$ Our cohort of focus, people aged 25 to 64 , is also the population for which the educational information for decedents is most accurate.

Figure 3 shows that as the share of the population with college degrees has grown, overall mortality rates have moved closer to college-educated rates. The figure also displays the coefficient of variation for overall rates, which has risen from 0.154 to 0.212 , an increase of more than one-third. In addition, Figure 3 illustrates the widening gap between college and non-college mortality, a result consistent with Case and Deaton's finding that educational differences in mortality are becoming more pronounced over time. ${ }^{3}$ For example, West Virginia and Kentucky - two states with generally high mortality rates - experienced significant increases in their non-college-educated mortality rates from 1992 to 2016, even as their college-educated mortality rates fell. There is also greater spatial variation in non-college mortality rates, consistent with Chetty et al. (2016), who suggest that spatial variation in mortality is larger for people in lower income groups.

Most importantly, there was considerable movement in state-level mortality rankings from 1992 to 2016. We show a striking example by highlighting California and Ohio in each panel. In 1992, overall mortality rates for these two states were virtually identical. During the 1990s, however, the mortality experiences of the states diverged, so that by 2016, the overall mortality rate in California was the second lowest in the nation, while the rate in Ohio was the 10th highest.

The California-Ohio comparison is consistent with one of the hypotheses discussed earlier: Mortality rates in high-education states such as California could have declined by more due to the national mortality trend favoring higher-educated people. We therefore want to ask whether health improved so much in California (and states like it) because these states' populations initially had higher fractions of college-educated adults, or because those fractions grew over time.

The role of education in driving mortality dispersion across states can be evaluated with

Age-adjustment is done by weighting the raw mortality rates of 10-year age groups in each state and year by shares of population that are constant across states and years. Specifically, the weights used are the standard 2000 reference population weights, drawn from Table V in the Technical Notes of National Vital Statistics Reports, "Deaths: Final Data for 2017," (Kochanek et al. 2017).

${ }^{2}$ Four states began collecting education data on death certificates much later: Oklahoma in 1997, Georgia in 2010, South Dakota in 2004, and Rhode Island in 2015; as a result, we omit these states from the analysis. For the remaining states, as with other research in this area, the lack of educational information for some decedents requires us to impute this information; following Case and Deaton (Case and Deaton 2017), we do this based on the fraction in each education group by year, race, sex, age group, and cause of death; for all-cause mortality, we additionally impute based on state of residence.

${ }^{3}$ Our broad measures of college graduates and non-college graduates are likely to mask heterogeneity in educational attainment within these groups. For a discussion of heterogeneity in the non-college group, see Novosad, Rafkin, and Asher (2020). 
a simple statistical model. In any given year, a state's overall mortality rate can be thought of as a weighted average of the individual mortality rates for its college-educated and noncollege-educated populations, with the weights for this average depending on the state's college-educated population share. In turn, we can think of the state's college-educated mortality rate as the overall mortality trend for all college-educated Americans in that year, plus a state-and-year specific residual. Similarly, the state's non-college rate can be decomposed into the overall national mortality trend for college-educated Americans, plus an additional factor to capture the high (and rising) mortality penalty faced by non-collegeeducated Americans, plus a non-college state-year residual. So for a given year, we can characterize each state's mortality rate as:

Overall state mortality rate $=$

(state's college population share) $\times$

(national college mortality rate + state's college mortality-rate residual)

$+$

(state's non-college population share) $\times$

( $\underbrace{\text { national college mortality rate }+ \text { national non-college mortality penalty }}$

national non-college mortality rate

+ state's non-college mortality-rate residual).

This framework allows us to allocate the growing state-level divergence in mortality rates across four channels:

(a) Changes over time in college population shares across states. These changes could arise from state-level differences in college attendance or from differences in net migration rates of college-educated persons. Because college-educated mortality rates are lower than non-college-educated rates, changes in college-educated population shares across states could increase dispersion in overall state mortality.

(b) An increase in the mortality penalty for Americans without a college education. Holding constant college-educated population shares, the well-documented increase in the mortality penalty for non-college-educated Americans would tend to raise relative mortality in states with relatively few college graduates.

(c) An increase in the standard deviation of the state-level mortality residuals for collegeeducated residents. This residual captures any difference between national and state mortality rates among college-educated persons. A gap between a state's college-educated mortality rate and that of the nation could stem from the state's investments in health (interpreted broadly to include public and private health investments), taxes on products that impact health (such as tobacco and alcoholic beverages), and from differential health behaviors. For example, as information about nutrition, exercise, and tobacco's roles in health increased, college graduates in states such as California may have adopted healthy behaviors more often 
than college graduates in the nation as a whole.

(d) An increase in the standard deviation of the state-level mortality residuals for noncollege-educated residents. Similar to the college residual, this term captures the difference between state and national mortality rates among non-college-educated adults. Like the college residual, the non-college residual will arise from state-specific policies, taxes, and behaviors that matter for mortality. Examples especially relevant for the non-college-educated population include state-level minimum-wage legislation or the generosity of programs such as Medicaid. State regulations promoting clear air and water could also affect the non-collegeeducated population disproportionately if these individuals tend to live in environmentally stressed communities.

Figure 4 shows how each of these channels contributes to the growth of state-level dispersion. On the vertical axis is the standard deviation of (log) mortality rates across states, with dispersion rising from 0.12 in 1992 to 0.19 in 2016. The baseline is a flat line because it holds all components of state mortality - college-educated population shares, national mortality rates, and state- and education-specific residuals - constant at their 1992 levels. The other lines in the figure depict standard deviations of the log state mortality rates that are implied when the 1992 values of selected model components are replaced with their actual values. For example, replacing each state's 1992 college-educated population share with its actual evolving college-educated shares (channel a) has only a modest impact on the implied standard deviation of log mortality rates across states, while replacing the 1992 national non-college-educated mortality penalty with the rising actual values of this penalty (channel b) adds a bit more. Combined, however, these two channels account for less than one-sixth of the total increase in the state-level standard deviation over time. Rising variation in the standard deviation of actual state-level college residuals (channel c) adds an additional 6 percent, but the lion's share is caused by the increase in the standard deviation of residuals for non-college-educated residents (channel d), which accounts for more than three-quarters of the increase in overall dispersion. ${ }^{4}$

Why is the contribution of non-college residuals so high? In part, the non-college component is likely to account for a larger share of the standard deviation simply because college graduates typically make up less than 30 percent of the total population. ${ }^{5}$ That said, there is independent evidence that variation in mortality among less-educated or lower-income persons is an important reason why mortality rates vary so much geographically. Montez et al. (2019), studying education and mortality from the 1980s through 2011, find that educa-

\footnotetext{
${ }^{4}$ Counterfactuals vary according to which variables are changed to actual values first, but in the appendix we show that our general results are robust to the order in which each channel is introduced.

${ }^{5}$ Additionally, because we base our model on the natural log of mortality rates, equal percentage changes in college and non-college rates, combined with higher average rates for non-college populations, will show up as a larger contribution of non-college rates to overall dispersion.
} 
tional differences in mortality across states grew primarily due to divergence among the less educated groups. Also, Chetty et al. (2016) link mortality records with individual income data to show that across local labor markets, mortality rates vary more at the bottom of the income distribution than at the top.

Yet our model indicates that the geographical variance in non-college mortality rates is not the whole explanation for rising dispersion in state-level mortality. Nor is this rising dispersion a mechanical consequence of the worsening national mortality penalty faced by non-college-educated Americans. Rather, the importance of both residuals in our framework of state-level mortality suggests that in some states, "place effects" have evolved over time to the benefit of both college-educated and non-college-educated residents, and these place effects turn out to be important in explaining why mortality has diverged over the last three decades. An important clue pointing to the importance of place effects is the high within-state correlation of non-college and college residuals produced by the model, which is relatively stable at around 0.70 in both 1992 and 2016. In an extension of this exercise described in the appendix, we show that assuming that each state's yearly place effect is an equally weighted average of its non-college and college residuals implies that place effects can explain much of the increased dispersion attributed to the two sets of residuals in Figure $4{ }^{6}$ Results such as these suggest that understanding the role of place in health is a key to understanding rising dispersion in health outcomes over time.

\section{Income and the Rising Divergence of State-Level Mor- tality Rates}

If place effects are large, one may reasonably ask whether these effects are mediated by other factors associated with mortality. An obvious candidate is income, which has been demonstrated at the micro-level to be an important predictor of early mortality (see Chetty et al. (2016), among many others).

In Figure 5, we plot state-specific midlife mortality rates against state-level per capita income in selected years. Our income measures are based on estimates from the Bureau of Economic Analysis of total personal income received by the residents of individual states in each year. In this definition, income can include wages and salaries, profits from businesses and farms, payments due to ownership of financial assets, and government transfers, but not capital gains. Per capita income is defined as total personal income divided by state population as of July 1 of that year, and expressed in 2012 dollars using the price deflator

\footnotetext{
${ }^{6}$ Rather than using an equally weighted average of residuals to create place effects, an alternative method would use national shares of college and non-college graduates over the time period considered.
} 
for personal consumption expenditures. Because the mortality rates are not broken down by education, we can use public-use mortality data and extend the analysis to 2019.

The upper-left panel of the figure plots mortality against income in 1968. In this year, the correlation between mortality and per capita state income was negligible, at -0.20 . Residents of New York and California in 1968 had higher average incomes than residents of Arkansas and Ohio (as they do currently), but in that year state-level mortality was similar across all four states. The upper-right panel shows that in 1980, the correlation between income and mortality was largely unchanged from 1968, even as incomes grew. By 2019, however, state mortality rates had lined up largely in lockstep with income. The lower-left panel shows a negative and significant correlation between income and mortality equal to -0.71 .

At first glance, a strong correlation between income and mortality in the 2019 cross section might suggest that changes in economic conditions (such as income or unemployment rates) predict changes in mortality. Instead, we find a more subtle pattern. The dramatic lining up of income and mortality in the lower-left panel of Figure 5 was not so much a shift in income rankings across states, but rather a reshuffling of state-level place effects. Over time, midlife mortality has become increasingly correlated with the level of income, a result that, except for Pinkovskiy (2019), we had not previously seen. For example, during this period mortality rates fell rapidly in New York and California while in Ohio and Arkansas they barely budged. Because high-income states in 2019 were typically high-income states in earlier years, we can express the lining up of mortality and income with income data from previous years, as we do in the lower-right panel of the figure. This panel shows that mortality in 2019 is also strongly negatively associated with state-level per capita income from more than 50 years earlier, with a correlation of -0.65 . Taken together, these correlations strongly suggest that the greater dispersion of mortality levels across states is not being driven by the growing dispersion of income levels; that is, state-level changes in income do not explain state-level changes in mortality. This result is also supported by other analyses, including those by Case and Deaton (2017) and Ruhm (2018). Instead, mortality changes have been most favorable in those states that have tended to have high relative levels of income over the past three decades.

An obvious candidate to explain the growing correlation between midlife mortality and income is the growing rate of deaths of despair. Case and Deaton not only document the explosive increase in these deaths during the 21st century, they also show that spatial dispersion of these deaths has risen dramatically over the same period (Case and Deaton 2017). As they emphasize, the dramatic growth in midlife mortality is strongly correlated with education. Among college graduates, deaths of despair have remained largely unchanged and show little variation across states. By contrast, in the non-college-educated population, deaths of despair have risen sharply, with a particular impact in states such as West Virginia, New 
Mexico, Ohio, New Hampshire, and Massachusetts (Case and Deaton 2020). If deaths of despair have been concentrated in low-income states, then their recent growth could potentially explain the strengthening correlation between state-level income and mortality that we have documented.

Although deaths of despair clearly have contributed to the widening geographic disparity in mortality rates across states, they are not the primary cause. To see this, note that measured dispersion in midlife mortality has been growing rapidly even when deaths of despair are excluded from the analysis. Figure 6 depicts the coefficient of variation of midlife mortality rates with and without deaths of despair from 1992 through 2016. During this period, the coefficient of variation of mortality rates for deaths excluding deaths of despair increased by 67.9 percent, almost identical to the 68.7 percent increase in variation for all-cause mortality rates. ${ }^{7}$

A key reason that deaths of despair do not completely explain rising dispersion is that even when their rapid recent growth is considered, these deaths account for only about one-sixth of all deaths at midlife. (Deaths of despair account for a larger fraction of lifeyears lost because such deaths tend to occur at younger ages.) The top panel of Figure 7 displays midlife mortality rates in selected years from 1992 through 2016 for deaths of despair and for four of the leading causes of death: cancer (more formally known as malignant neoplasms), heart disease, cerebrovascular diseases, and chronic lower-respiratory diseases. Not surprisingly, deaths related to cancer and heart disease, leading causes of death for the population as a whole, are the most common at midlife in 1992. Also notable is the dramatic reduction in death rates for these two diseases, as well as the well-documented (but still unexplained) slowdown in the reduction in heart disease deaths after 2008. Deaths of despair, while more common at midlife than deaths due to cerebrovascular disease and chronic lower-respiratory disease, were less common than cancer or heart disease deaths in 1992. By 2016, deaths of despair killed as many Americans aged 25 to 64 as did heart disease but fewer than cancer.

The lower panel of Figure 7 displays the correlation between these causes of death and contemporaneous state income for the same years. Across all causes in the figure, state-level income became more negatively correlated with death rates from 1992 through 2016. Yet while the income correlation for deaths of despair follows this pattern for most of the 1990s and early 2000s, the correlation later reverses course and becomes less negative. It is likely that the introduction of fentanyl and other synthetic opioids in recent years has changed the nature of the overdose crisis in the United States, weakening the correlation between

\footnotetext{
${ }^{7}$ We acknowledge that the number of deaths of despair is likely understated because of underreporting; a drug overdose might be incorrectly reported as a heart attack (Glei and Preston 2020; Vierboom, Preston, and Hendi 2019). However, the state-level correlation between the growth in deaths of despair and in other deaths is just 0.35 , so biases are likely to be limited.
} 
state-level income and deaths of despair in the process.

Our earlier example of Ohio and California from Figure 3 helps to illustrate how deaths of despair relate to overall patterns of mortality. As noted earlier, mortality rates in Ohio and California were similar in 1992 (401 deaths per 100,000 in California versus 398 in Ohio). Over time, deaths of despair grew by much more in Ohio, so that by 2016 Ohio ranked thirdhighest among all states in these deaths. But overall mortality in Ohio did not change much over this period, as its large increase in deaths of despair (63 per 100,000) was nearly offset by a decline in other deaths (50 per 100,000). California, on the other hand, experienced a significant decline in overall mortality, to just 270 per 100,000 by 2016. This decline resulted from a small increase in deaths of despair (2 per 100,000) that was swamped by a decline in California's other deaths of 133 per 100,000 - almost three times the fall in Ohio. All told for these two states, deaths of despair accounted for about 40 percent of the widening gap, with the much greater decline in other deaths in California responsible for the remainder.

The ultimate relationship between opioid use, deaths of despair, and regional economic conditions is undoubtedly complex. Several papers find that exogeneous shifts in manufacturing employment tend to raise adverse opioid-related outcomes (Autor, Dorn, and Hanson 2019; Pierce and Schott 2020; Charles, Hurst, and Schwartz 2018). However, the sizes of the estimated effects are too small to explain much of the massive increase in the number of opioid deaths during the last several years, and some evidence suggests that reductions in manufacturing employment reduce mortality from other causes, such as heart disease (Pierce and Schott 2016). Additionally, regional patterns of deaths of despair are strongly influenced by factors that have little to do with changes in a region's economic conditions. These factors include the growing availability of high-grade heroin at low prices (Quinones 2015) or floods of cheap, illicit, and lethal fentanyl into some communities. Indeed, in the 12 months leading up to May 2020, California experienced an alarming surge in overdose deaths in particular communities (Kurle 2021).

When relating previous research on the economic determinants of health to our results in this section, two things are important to keep in mind. The first is that much of the earlier work relates changes in economic conditions to changes in health outcomes. This approach implicitly assumes a stable relationship between economic conditions and health; if incomes in an area decline, then health also declines due to the constant income-health relationship. But as Figure 5 shows, the income-health relationship itself is changing, as income becomes an increasingly powerful predictor of mortality. A second thing to remember is the long-run nature of the disparities that we have analyzed. Health in richer states has been improving more than in poorer states for several decades, so the causes of this divergence likely run deeper than short-term fluctuations in employment or income. Case and Deaton (2017) make a similar point regarding deaths of despair, pointing out that neither state-level measures of 
income nor changes in income predict the recent rise in the number of these deaths. In their view, deaths of despair are increasing not because of short-term economic fluctuations but rather because of a long-run devaluation of the work performed by persons without college degrees. Their recent book (Case and Deaton 2020) catalogs the devastating effects that this devaluation has had on America's social fabric during the last several decades.

To explain the long-run pattern of mortality differences across states - specifically the strengthening correlation between income and mortality - we also adopt a long-run perspective. In the next section, we contend that the association between state-level income and mortality is probably not a true causal relationship. Instead, the strengthening link between mortality and income reflects differences in regional resources, population behavior, and health-related policies that, over time, have contributed to larger mortality declines in richer states than in poorer ones.

\section{A Portmanteau of State-Level Factors}

Our framework for thinking about rising dispersion in state-level mortality has two main components. The first is that health at any point in time is largely determined by decisions made in the past, just as an economy's output of goods and services depends largely on the stock of physical capital built up by past investment. Indeed, health economists often use the concept of "health capital" to capture this phenomenon (Grossman 1972; Case and Deaton 2005). Individuals invest in health capital though behaviors such as regular exercise and maintaining a proper diet. Health capital depreciates over time at a rate that increases with age and in response to factors such as poor health behaviors, stress, and physically demanding occupations (Cutler, Meara, and Stewart 2020). The health-capital framework suggests that various factors have long-lasting effects that "come home to roost" in midlife mortality data many decades on. Given the evidence on the long lag time in health behaviors affecting mortality (Fenelon and Preston 2012), we should expect to observe smoking, obesity, pollution, and stress related to adverse economic conditions several decades ago gradually reflected in current midlife mortality (Preston, Vierboom, and Stokes 2018).

A second observation useful for understanding health dispersion is that states differ greatly in their health investment and depreciation rates. The classic example of this phenomenon comes from Victor Fuchs (1974), who observed that Utah exhibited much lower mortality than neighboring Nevada, despite similar levels of income, education, and access to health care. Fuchs argued that this gap could be explained by differing behavior in the two states, noting that rates of smoking, drinking, and family instability were much lower in Utah (where the majority of residents are members of the Mormon Church) than in Nevada. State-level differences in health investment and depreciation rates can also be influenced by 
policies related to health. States that instituted high cigarette and liquor taxes, or that expanded Medicaid under the Affordable Care Act, might expect to see reduced rates of smoking and drinking, and improved rates of health investment and depreciation among their residents.

Our hypothesis is that the widening divergence in midlife mortality and the tightening relationship between mortality and income reflect the long-run effects of varying behaviors and policies related to health capital during the last several decades. The data suggest that residents of high-income states have enacted policies and adopted behaviors with long-run payoffs to midlife mortality that are becoming increasingly apparent over time.

One question raised by this hypothesis is why health outcomes are diverging so much now - why hasn't health always been better in high-income states than in low-income states? In 1992, high-income states were no more likely than low-income states to experience lower mortality. It was certainly not because high-income people at the time were sicker; individuallevel analyses using data from the same period demonstrate a strong negative income gradient in mortality (Pappas et al. 1993), and a similar negative relationship between smoking and income was also apparent. Nor can lagged health effects explain this surprising result; unlike the strong link between 1992 income and current state-level mortality, there is only a weak association between state-level income in 1968 and mortality rates in 1992.

To explain why state differences in mortality have become more aligned with state-level variables such as income since about 1990, we instead hypothesize that in the middle of the 20th century, social structures in low-income states provided more safeguards against adverse health outcomes. Perhaps more importantly, during this period there may have been more opportunities for risky behavior in high-income states. Black et al. (2015) show that African Americans who migrated from the Deep South during the Great Migration experienced higher levels of mortality than those who stayed home, conditional on their initial health statuses. Although migrants may have had higher incomes in the North, "health benefits due to economic and social improvement were apparently swamped by other forces, such as changes in behavioral patterns that were detrimental to long-term health, including higher propensities to smoke and consume alcohol" (p. 501). ${ }^{8}$ By the late 20th century, however, high-income states were more likely to enact health policies that over the next quartercentury resulted in more effective safety nets, more rapid diffusion of effective pharmaceutical treatments, a reduction in smoking, and a consequent decline in all-cause mortality (Montez et al. 2019, 2020; Miller and Wherry 2019; Buxbaum et al. 2020).

The hypothesis that health policies matter for the evolution of mortality has empirical support from a growing literature on Medicaid. Several authors, drawing upon different time

\footnotetext{
${ }^{8}$ Further evidence on the importance of state policies comes from Kansas, which imposed prohibition in 1880 and did not end it until 1948. Perhaps not coincidentally, in 1959 Kansas was tied in first place for the state with the highest life expectancy.
} 
periods and settings, show important evidence of plausibly causal reductions in mortality and morbidity linked to state differences in Medicaid policies. Owing to Medicaid eligibility's link with Aid to Families with Dependent Children (AFDC), a program dating to 1935, there was substantial cross-state variation in the shares of newborns eligible for Medicaid. Using that variation, Goodman-Bacon (2018) estimates that infant mortality fell for newborn cohorts after Medicaid's implementation in the 1960s and 1970s, especially in states with higher rates of eligibility for Medicaid. In the aggregate, nonwhite infant mortality fell by 11 percent in relation to Medicaid's implementation, and it did so for the causes of death amenable to medical intervention at that time (Goodman-Bacon 2018). Later expansions of Medicaid (in the late 1980s and early 1990s) to newborns and pregnant women with slightly higher incomes also coincided with reductions in infant mortality (Currie and Gruber 1996). And states that expanded eligibility for Medicaid under the Affordable Care Act saw declines in mortality and morbidity among near-elderly adults (Miller, Johnson, and Wherry 2021).

Even more important for the time period we study, the implementation of Medicaid and its later expansions to pregnant low-income women have been linked to lower morbidity and mortality in the long run (Goodman-Bacon 2021; Miller and Wherry 2019). Again using state variation in eligibility for Medicaid when first implemented due to its link to state participation in AFDC, Goodman-Bacon (2021) estimates that "Medicaid added 10 million quality adjusted life-years for cohorts born between 1955 and 1975 and saved the government more than twice its original cost" (p. 2588). The latter point is important because states share up to half of Medicaid's program costs, so spending more crowds out other beneficial state spending. Later Medicaid expansions of the 1990s also had lasting effects, with infants whose mothers gained Medicaid coverage in the early 1990s experiencing lower rates of chronic conditions or hospitalizations for diabetes and obesity in adulthood (Miller and Wherry 2019).

Other health programs targeting low-income populations matter for the evolution of longterm health. Using variation in the opening of community health centers (CHCs) in the 1960s and 1970s (designed to care for medically under-served populations), Bailey and GoodmanBacon (2015) show that age-adjusted mortality rates had declined by an additional 2 percent in counties that opened CHCs compared to those that did not. Further, the mortality decline was driven by deaths among adults over age 50. This pattern is also consistent with the hypothesis suggested by Case and Deaton (2017) that cohorts entering the workforce in the 1970s and 1980s experienced a changed economic landscape, one that shifted particularly against people without college degrees.

Another important policy for health is environmental policy, since particulate pollution both sickens and kills, especially among vulnerable residents (Deryugina et al. 2019). A recent paper maps changes in particulate pollution in the United States from 1980 to 2016, 
to show that particulate pollution has declined everywhere, though not necessarily equally (Colmer et al. 2020). Returning to our example of diverging mortality rates in Ohio and California, it is interesting that pollution declined by more in Ohio than in California during this time period; West Virginia's improvement in air quality was among the country's greatest. Thus, policies to reduce particulate pollution seem unlikely to explain this pattern of diverging mortality across states.

Whereas the empirical work cited so far in this section investigates formal policies, a growing body of research examines differences in informal health-care practices across geographic areas. One example is the riskiness of prescriptions. Finkelstein, Gentzkow, and Williams (2019) find that Medicare patients moving from regions with low levels of opioid prescriptions to regions with high levels are more likely to receive risky opioid prescriptions in their new communities. More generally, the question of whether the overall quality of health care has been converging or diverging across geographic areas during the past three decades is unresolved (Skinner and Staiger 2015). As discussed above, exposure to Medicaid improves long-term health outcomes for children and adults, but quantifying Medicaid's contribution to overall state-level differences in health is a subject of ongoing research.

All told, there is strong empirical support for the notion that specific health-related policies and behaviors differ across states, and that these differences matter for mortality. But quantifying how much of the total rise in state-level mortality dispersion can be explained by a health-capital model is more ambitious, due to the long lags between investments and outcomes and the myriad types of policies and behaviors that might be relevant. It is even more difficult to quantify the separate contributions of policies versus behavior, given the likely feedback between these two "inputs" into the health-capital framework.

Even so, the health-capital model can help us understand some puzzles in the empirical literature. For example, one type of behavior - smoking - typically has a far greater effect on mortality than its direct clinical impact would predict (Cutler et al. 2011). Consistent with a broad health-capital model, Montez et al. (2019) observe that the outsized effect of smoking on health in area-level regressions can be understood by noting that changes in smoking behavior are often correlated with changes in health-related policies, including policies unrelated to smoking. In New York, for example, smoking rates in 1992 were 22.1 percent, about the same as in North Dakota (21.9 percent) and only slightly below Mississippi's rate (23.6 percent). By 2016, smoking had fallen to 9.2 percent in New York, compared with significantly smaller decreases in North Dakota (14.0 percent) and Mississippi (16.6 percent). Since the early 1980s, New York has imposed a substantial excise tax on cigarettes, which reached $\$ 4.35$ per pack in 2016. But as Montez et al. argue, the higher cigarette tax in New York was part of a bundle of initiatives that, to one extent or another, tended to improve public health. For example, New York also participated in Medicaid expansion, implemented 
its own earned income tax credit, and set a minimum wage above the federal level $(\$ 9.00$ per hour in 2016). In contrast, Mississippi has a negligible cigarette tax (\$0.68 per pack in 2016), opted out of Medicaid expansion, does not offer its own earned income tax credit, and defaulted to the federal minimum wage. In addition, Mississippi has preempted local governments from implementing health-promoting legislation, such as paid sick days, a higher minimum wage, stricter firearm regulations, and nutrition labeling in restaurants.

To explore the potential impacts of state-level differences in policies and behaviors, we experiment with regressions with state-level mortality as the dependent variable and various explanatory variables, including smoking and obesity rates. To capture state-level economic factors, we include state-level income, poverty rates, and manufacturing employment shares. We also include rates of prescribing effective or risky drugs, intended to capture healthcare quality in 2008 through 2010 (Munson et al. 2013). Of course, these regression results should not be viewed as causal, and even interpreting the coefficients is tricky given the well-understood risks of using aggregated data to make inferences about individual causal factors. ${ }^{9}$

Details of these regressions and the underlying data sources are available in the appendix. Here, we simply note two general patterns that emerge. First, consistent with our earlier results on state-level income and mortality, income has a strong negative correlation with mortality in 2016 but no particular relation in 1992. However, when we include the additional control variables, the later income coefficient becomes much less negative. This reduction suggests that high-income states differ from low-income states along a variety of dimensions relevant for health that are being captured in some ways by the additional controls.

Second, we find that the importance of smoking in these regressions is rising over time, even after we control for income. ${ }^{10}$ This is consistent with interpreting the state-level smoking rate as a "sentinel measure" of midlife mortality, with lower smoking rates reflecting a variety of public health efforts to encourage more healthy behavior. Indeed, one might view these evolving health-related factors proxied for by smoking as the dynamic equivalent of the static Utah-Nevada comparison by Fuchs (1974), in which behavior is influenced by policies, and vice versa.

\footnotetext{
${ }^{9}$ This is sometimes referred to as the "ecological fallacy." As Gelman (2009) points out, the 15 poorest American states voted Republican in 2004, yet an analysis of individual-level data demonstrates a positive association between income and Republican voting.

${ }^{10}$ State-level smoking data come from the Behavioral Risk Factor Surveillance System (BRFSS) from the Centers for Disease Control and Prevention. BRFSS is an annual set of telephone surveys that collects state-level data on health behaviors. We use the BRFSS's post-stratification weights to construct state-level shares of daily smokers and obesity, where daily smokers are defined as respondents who reported smoking every day and having smoked at least 100 cigarettes throughout their lifetime. We also considered obesity, defined as having a body mass index greater than 30.0, but it was much less predictive of mortality. See the appendix for further details of our regressions. See Friedson et al. (2021) and Pinkovskiy (2019) for other recent area-level analyses relating smoking to health.
} 


\section{Conclusion}

We have documented a sharp increase in state-level disparities in midlife mortality, a result consistent with an emerging epidemiological literature (Vierboom, Preston, and Hendi 2019; Montez et al. 2019). This divergence has contributed to a more unequal America; West Virginia's midlife mortality rate is about double that of Minnesota. These widening geographic disparities in state-level mortality cannot be attributed to changing spatial patterns in education levels, income inequality, or increasing numbers of deaths of despair. Instead, rising spatial inequality in midlife mortality results from some states experiencing dramatic overall declines in mortality across educational groups, while other states have experienced at best only modest progress. The first-order question is why high-income states have done so much better. Our review of the evidence indicates that differential adoption of policiessuch as tobacco taxes, Medicaid expansions, and income support-in high-income but not low-income states has led to both widening spatial disparities in mortality and to an increasingly close negative association between income and mortality. These policies are distinct from but complementary to health-related behaviors that also differ across states.

We are certainly not the first to observe the importance of place for health, and there is a long-standing literature in geography and social epidemiology on the estimation and interpretation of place effects (McLafferty 2020). In the economics literature, there is a growing interest in estimating causal effects of place that abstract from selection effects that arise when, for example, people in poor health move to low-income neighborhoods lacking access to medical care (Jokela 2014). Studies of people who move can adjust for such selection, particularly when moves are randomized or exogenous (Chyn and Katz 2021). For example, randomized housing vouchers (Kling, Liebman, and Katz 2007; Ludwig et al. 2012) caused families receiving public housing vouchers to leave low poverty neighborhoods, while the destruction of large public housing projects (Chyn 2018) induced moves to lower poverty neighborhoods. Deryugina and Molitor (2020) examined older residents of New Orleans, many of whom moved after Hurricane Katrina in 2005. A notable finding was that average eight-year survival rate for all Medicare beneficiaries living in New Orleans in 2005 was 2 percentage points higher than expected in the absence of Katrina, even after residents who remained in New Orleans or who died due to direct or indirect effects of the hurricane are taken into account.

The causal place effects identified in the mover studies are conceptually different from the residual place effects we measure in our study; the short-term impact on health of moving from Mississippi to New York is different from the longer-term effects of growing up in Mississippi versus growing up in New York. For example, Finkelstein, Gentzkow, and Williams (2021) estimate that the causal effect of moving from, say, Florida to Minnesota is

potentially quite different from the residual "place" effects for residents of Florida compared 
with those in Minnesota. The cumulative effects of regional policies over the life cycleMedicaid coverage at birth, parental income support while a child, tobacco and alcohol taxes during adolescence, and higher-quality medical care during adulthood - are thus likely to exert a larger impact on life expectancy than the short-run impact of moving to a new neighborhood and changing physicians.

Going beyond mover studies to identify the determinants of place effects throughout the life cycle will be challenging. In particular, measuring the relative contributions of policies versus behavior on cross-state differences in health parallels the difficulty of disentangling the effects of institutions versus culture on cross-country differences in income. Two proponents of the importance of institutions in development observe that "England in the nineteenth century was ... a very unhealthy place, but the government gradually invested in clean water, in the proper treatment of sewage and effluent, and eventually in an effective health service" (Acemoglu and Robinson 2012, p. 51). The authors interpret these improvements not as the cause of England's rapid economic growth, but instead as a consequence of its economic success. Lessons from this literature on institutions have an encouraging policy implication: Although high-income states have shown the way, states with lower income capacity are not inexorably constrained to rates of midlife mortality that rank among the worst in developed countries. 


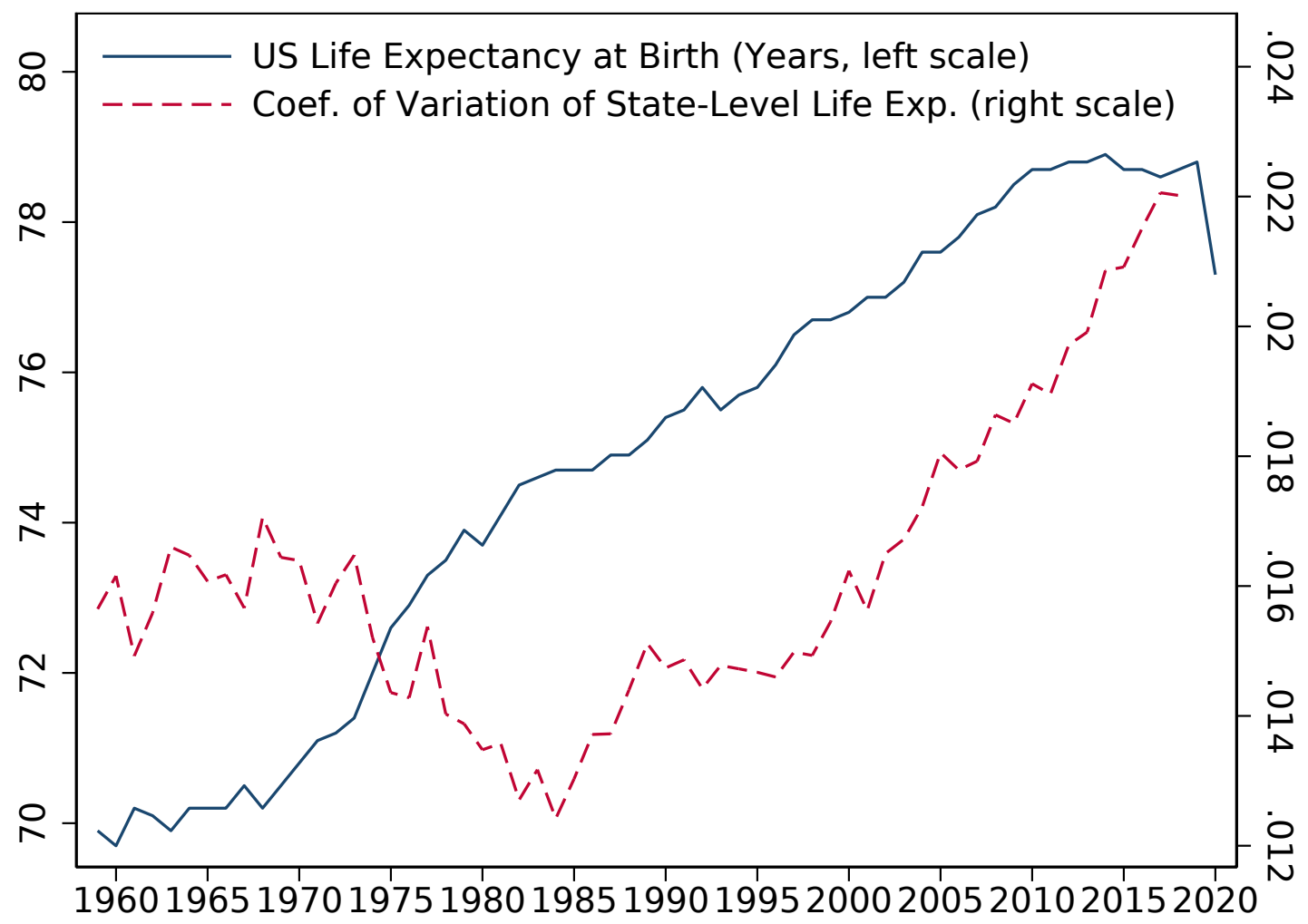

Figure 1. US Life Expectancy at Birth and State-Level Dispersion in Income. Note: The coefficient of variation is the population-weighted standard deviation of state-level life-expectancy rates divided by the national life-expectancy rate. Sources: The national life-expectancy rate (1959-2020) is from the National Center for Health Statistics, and state-level rates (1959-2018) are from the USA Mortality Database (https://usa.mortality.org). 

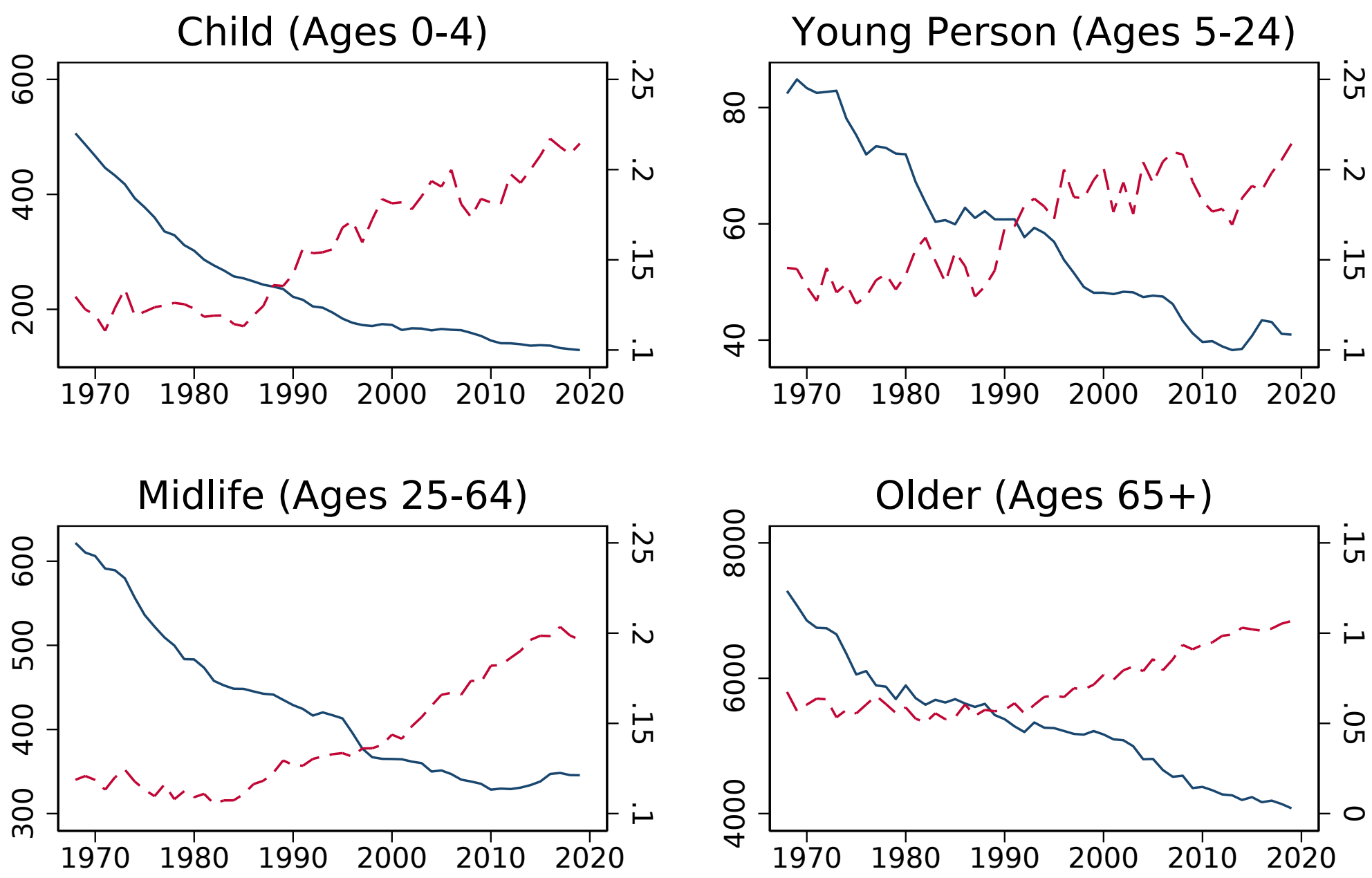

Mean (left scale)----- Coefficient of Variation (right \$cale)

Figure 2. Mortality Rates by Age Group (1968-2019). Note: Data are population-weighted statistics based on state-level age-adjusted mortality rates, defined as deaths per 100,000 persons. The coefficient of variation is the standard deviation of state-level mortality rates divided by the mean. Source: CDC Wonder database (https://wonder.cdc.gov/) 

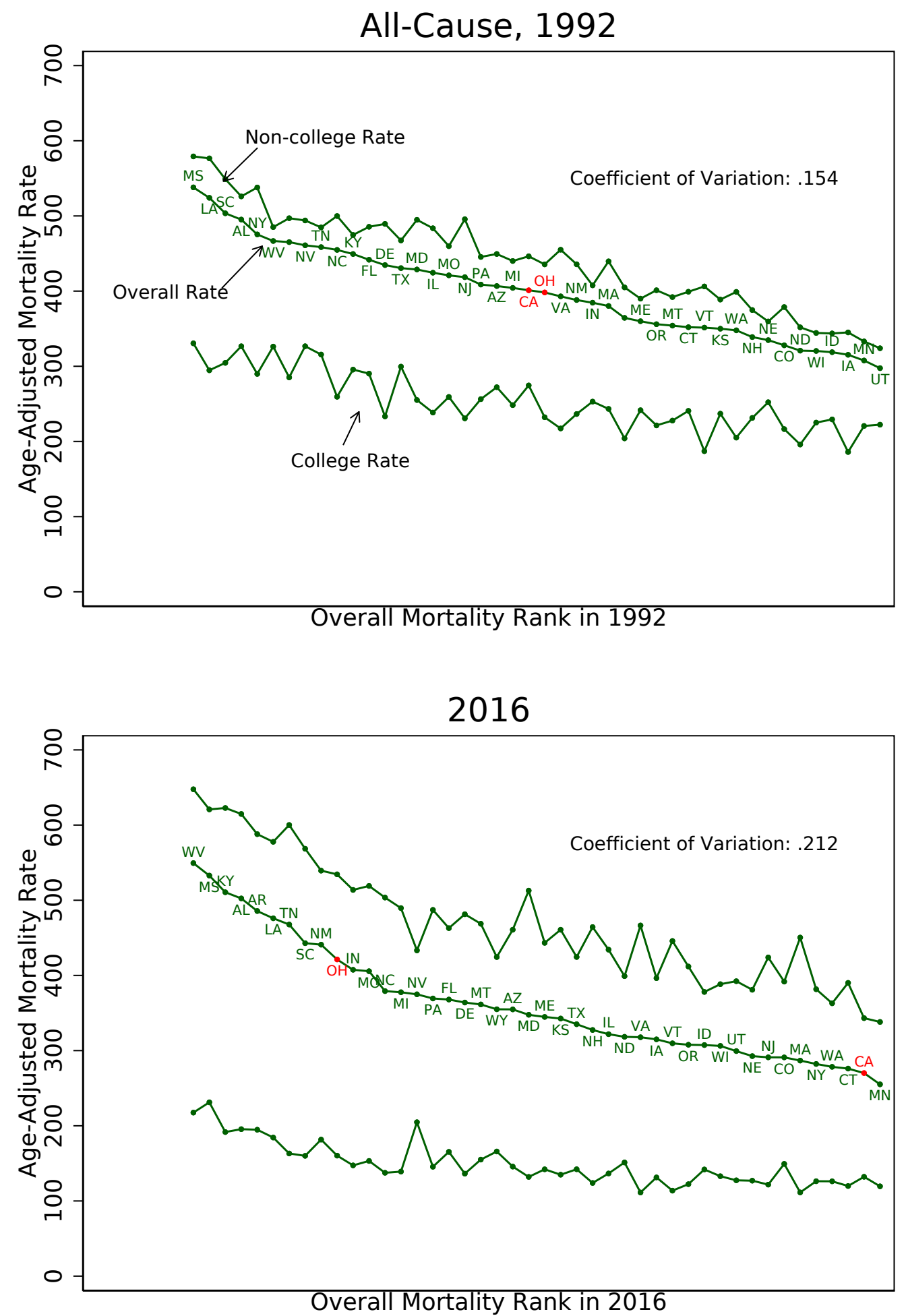

Figure 3. Education and Midlife Mortality at the State Level: 1992 and 2016. Note: The middle line in each panel (with accompanying state labels) depicts the all-cause mortality rate for all persons aged 25 to 64 in the given state and year. The top line depicts the mortality rate for persons in this age group who do not have college degrees, while the lower line depicts the midlife mortality rate of college graduates. Each panel also displays the coefficient of variation for overall mortality in the given year. All mortality rates are age adjusted. Source: Authors' calculations using individual-level mortality data from the National Center for Health Statistics. 


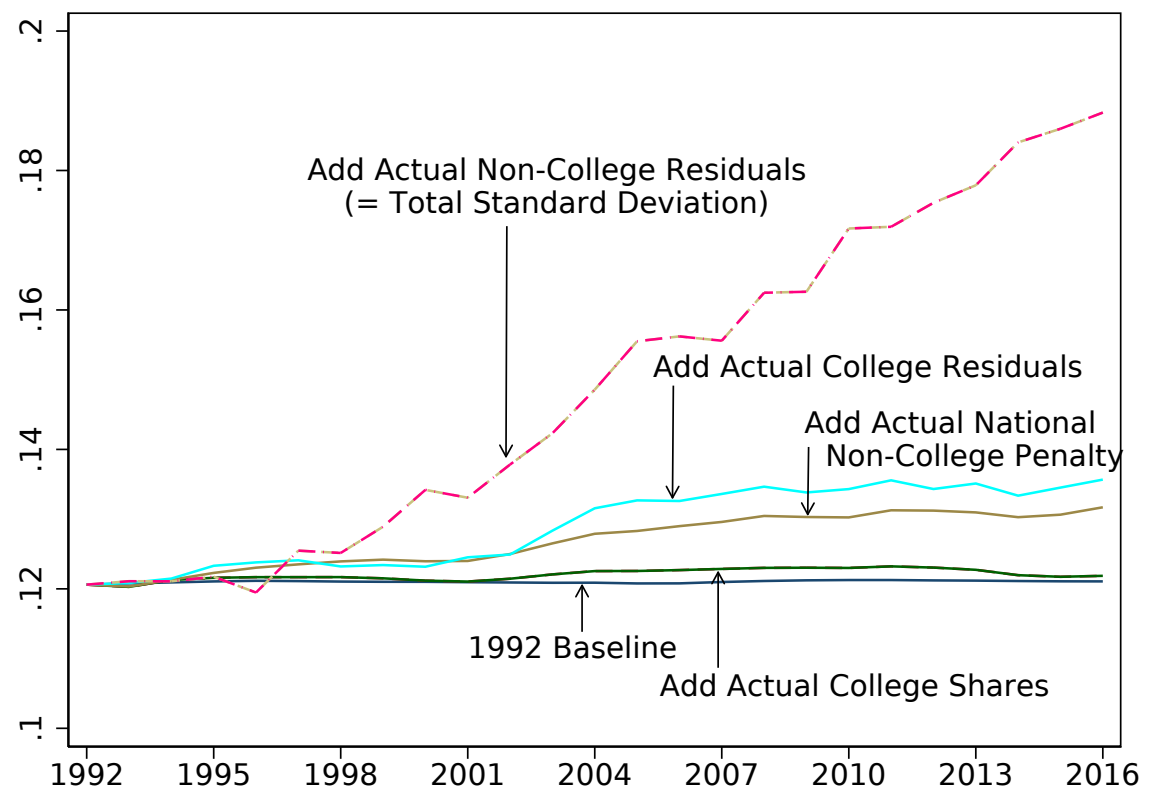

Figure 4. Decomposing the Rising Dispersion in State-Level Midlife Mortality Rates (19922016). Note: The dash-dotted line at the top of the figure depicts the actual population-weighted standard deviation of log midlife mortality rates at the state level. The solid line at bottom ("1992 baseline") depicts the constant standard deviation that would have resulted if each of the four components in the model described in the text had remained constant through 2016. The intermediate lines in the figure show the implied standard deviations after progressively adding each of the model's four components in the following order: actual college population shares, the actual national non-college mortality penalty, actual college mortality rate residuals, and actual non-college mortality rate residuals. The panel shows that changes in college shares and the national non-college penalty explain little of the rising standard deviation over time. Most of the increased dispersion is due to widening dispersion in non-college mortality rate residuals. Source: Authors' calculations using individual-level mortality data from the National Center for Health Statistics. 

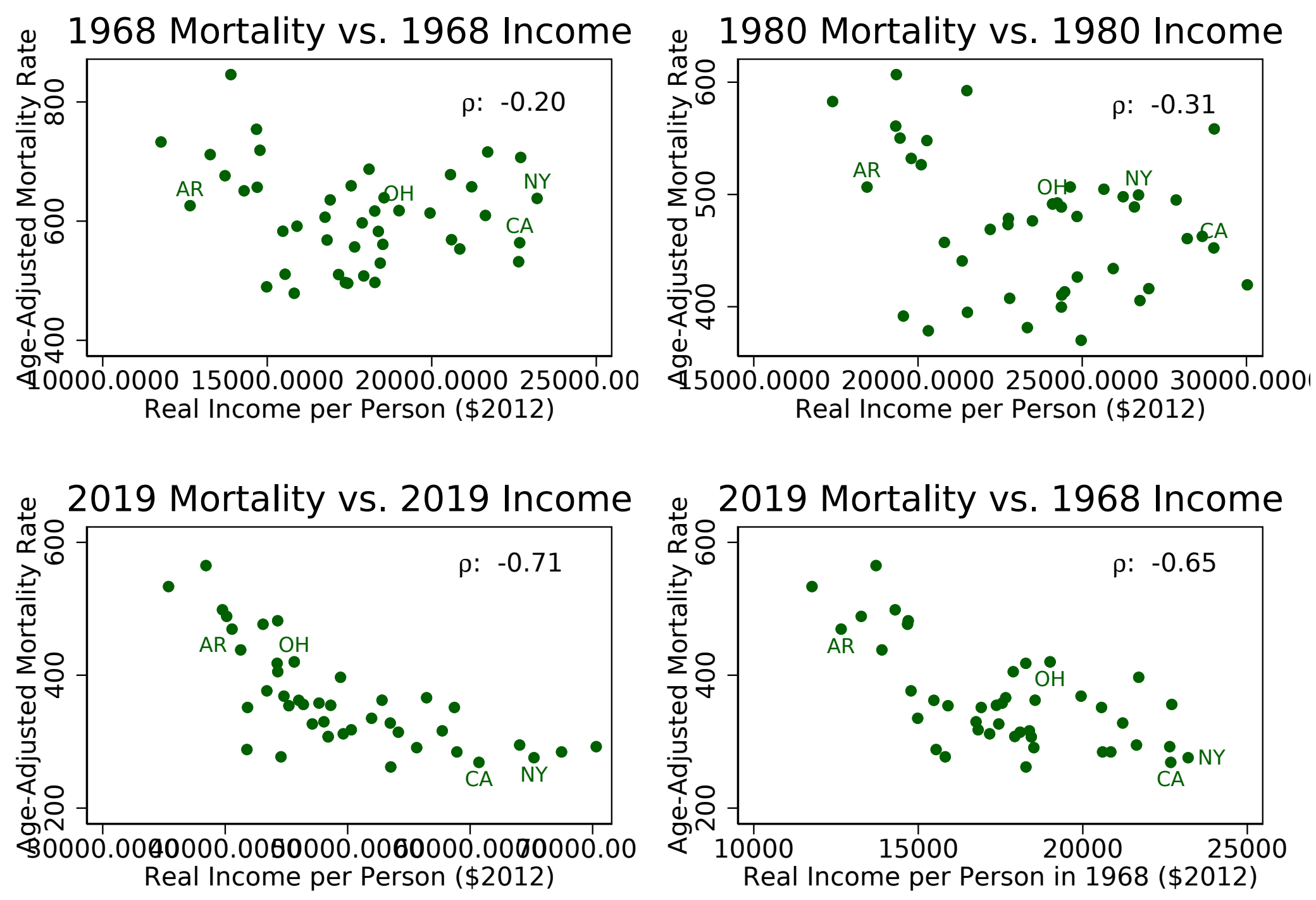

Figure 5. State-Level Income and Midlife Mortality Rates in Selected Years. Note: Mortality rates are age adjusted and correspond to all causes of death for persons aged 25 to 64 . State-level income is in 2012 dollars and corresponds to per capita personal income divided by the national chain-weight price index for personal consumption expenditures. Source: CDC Wonder database (for mortality rates) and the Bureau of Economic Analysis (for income and price index). 


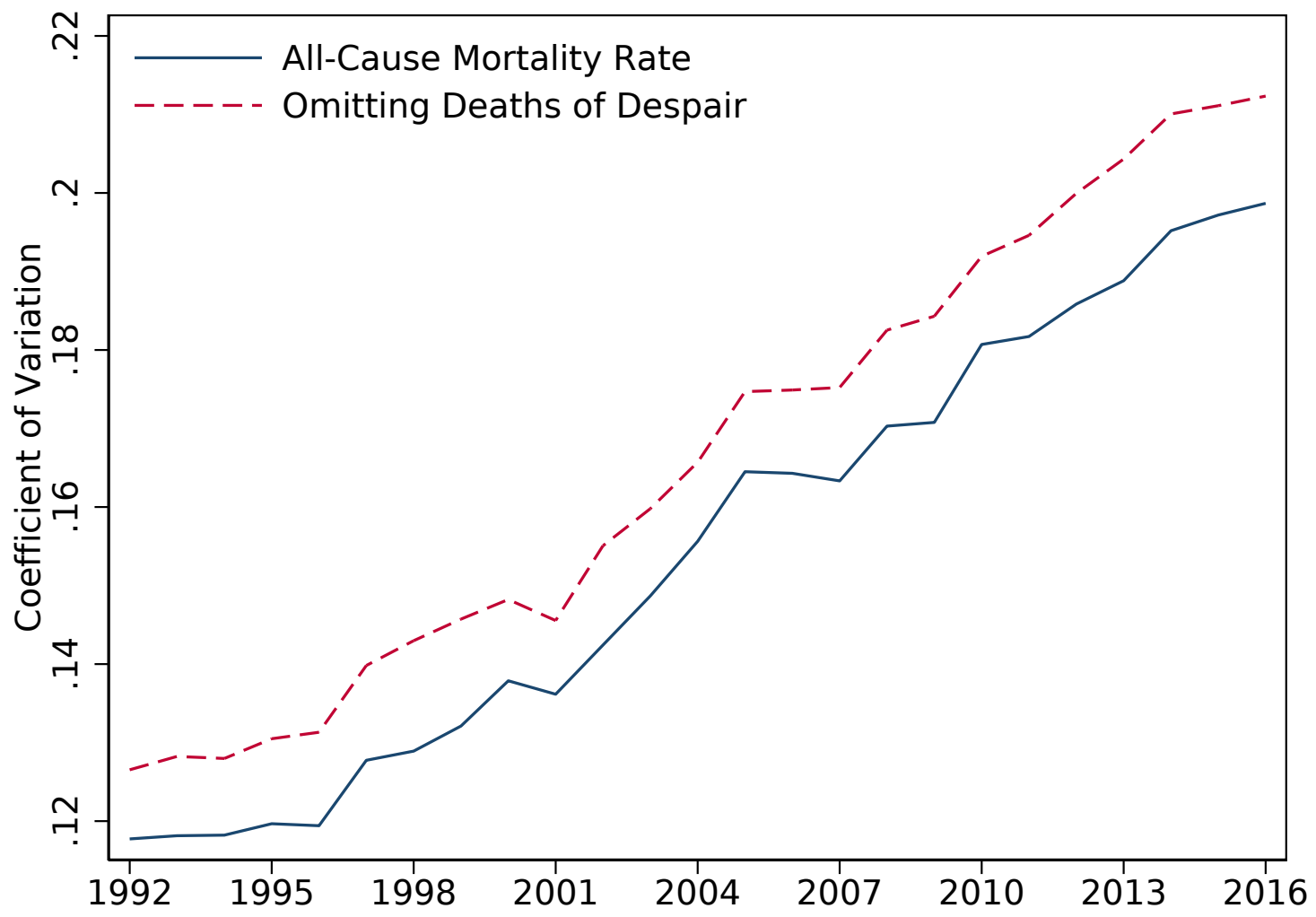

Figure 6. State-level Mortality-Rate Coefficient of Variation With and Without Deaths of DesPAIR. Note: Mortality rates are age adjusted and correspond to persons aged 25 to 64 . Deaths of despair are deaths attributed to cirrhosis (ICD9: 571; ICD10: K70, K73-74), suicide (ICD9: E950-959; ICD10: X60-84, Y87.0), or poisoning (E850-860, E980-982; ICD10: X40-X45, Y10-15). The coefficients of variation are population weighted Source: Authors' calculations using individual-level mortality data from the National Center for Health Statistics. 

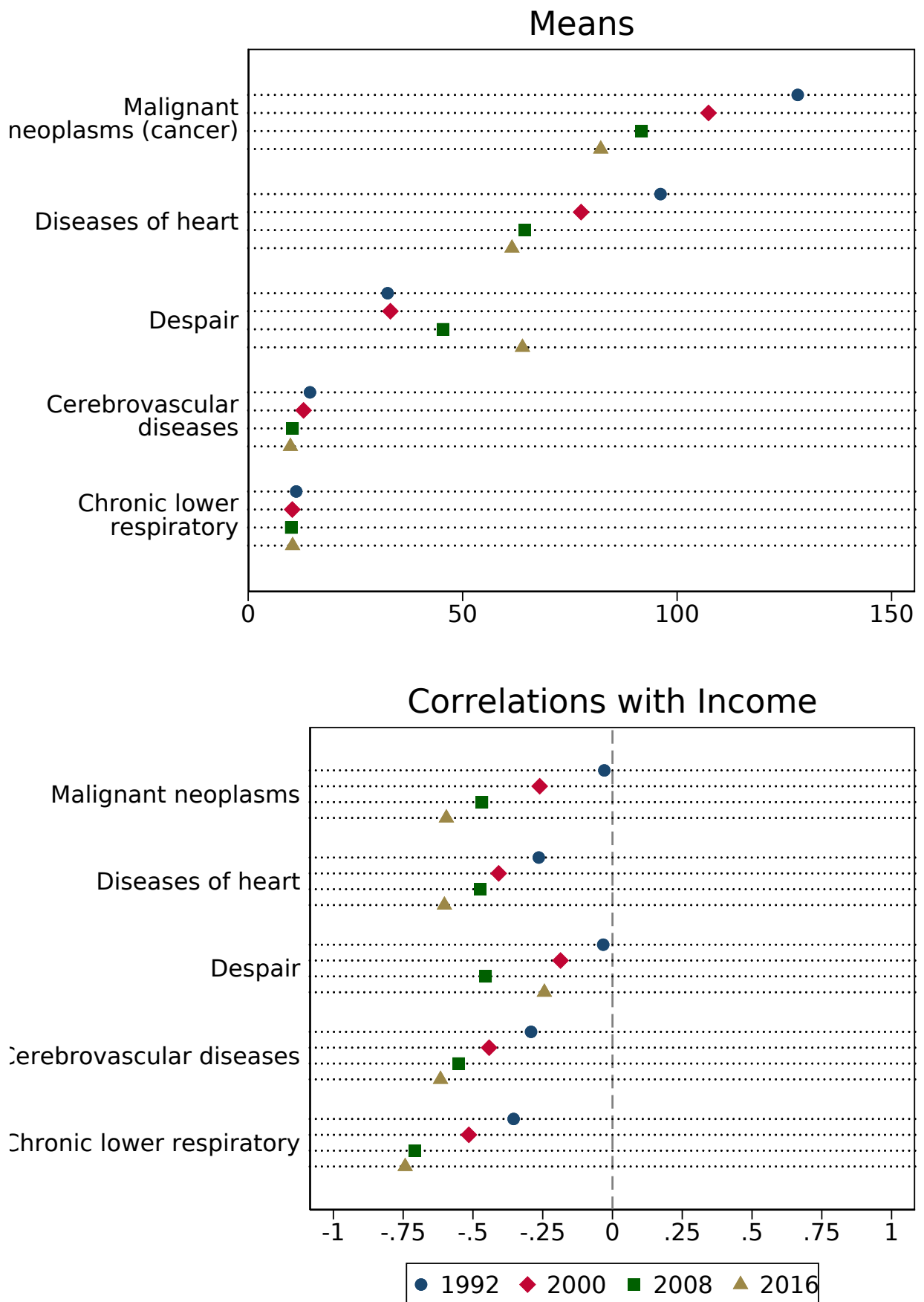

Figure 7. Selected Mortality Rates by Cause and Their Correlations with State-Level Income Over Time. Mortality rates are age adjusted and correspond to persons aged 25 to 64 . Means are population weighted. Deaths of despair are deaths attributed to cirrhosis (ICD9: 571; ICD10: K70, K73-74), suicide (ICD9: E950-959; ICD10: X60-84, Y87.0), or poisoning (E850-860, E980-982; ICD10: X40-X45, Y10-15). The remaining causes of death are malignant neoplasms (ICD9: 140-208; ICD10: C00-C97), diseases of heart (ICD9: 390-398, 402, 404, 410-429; ICD10: I00-I09, I11, I13, I20-I51), cerebrovascular diseases (ICD9: 430-434, 436-438; ICD10: I60-I69), and chronic lower respiratory diseases (ICD9: 490-494, 496; ICD10: J40-J47). Source: Authors' calculations using individual-level mortality data from the National Center for Health Statistics. 


\section{References}

Acemoglu, Daron, and James A. Robinson. 2012. Why Nations Fail: The Origins of Power, Prosperity, and Poverty. New York: Crown Publishing Group.

Autor, David H., David Dorn, and Gordon H. Hanson. 2019. "When Work Disappears: Manufacturing Decline and the Falling Marriage Market Value of Young Men." American Economic Review: Insights 1(2): 161-178.

Bailey, Martha J., and Andrew Goodman-Bacon. 2015. "The War on Poverty's Experiment in Public Medicine: Community Health Centers and the Mortality of Older Americans." American Economic Review 105(3): 1067-1104.

Black, Dan A., Seth G. Sanders, Evan J. Taylor, and Lowell J. Taylor. 2015. "The Impact of the Great Migration on Mortality of African Americans: Evidence from the Deep South." American Economic Review 105(2): 477-503.

Buxbaum, Jason D., Michael E. Chernew, A. Mark Fendrick, and David M. Cutler. 2020. "Contributions Of Public Health, Pharmaceuticals, and Other Medical Care to US Life Expectancy Changes, 1990-2015." Health Affairs 39(9): 1546-1556.

Case, Anne, and Angus Deaton. 2005. "Broken Down by Work and Sex: How Our Health Declines." In Analyses in the Economics of Aging, David A. Wise, ed., 185-212. Chicago: University of Chicago Press.

Case, Anne, and Angus Deaton. 2015. "Rising Morbidity and Mortality in Midlife among White Non-Hispanic Americans in the 21st Century." Proceedings of the National Academy of Sciences 112(49): 15078-15083.

Case, Anne, and Angus Deaton. 2017. "Mortality and Morbidity in the 21st Century." Brookings Papers on Economic Activity 2017 (Spring): 397-443.

Case, Anne, and Angus Deaton. 2020. Deaths of Despair and the Future of Capitalism. Princeton, NJ: Princeton University Press.

Case, Anne, and Angus Deaton. 2021. "Life Expectancy in Adulthood is Falling for Those Without a BA Degree, but as Educational Gaps Have Widened, Racial Gaps Have Narrowed." Proceedings of the National Academy of Science 118(11).

Centers for Disease Control and Prevention (CDC). 2021. "Behavioral Risk Factor Surveillance System (BRFSS)." US Department of Health and Human Services, Centers for Disease Control and Prevention. 
Charles, Kerwin Kofi, Erik Hurst, and Mariel Schwartz. 2018. "The Transformation of Manufacturing and the Decline in US Employment." In NBER Macroeconomics Annual 2018, Martin Eichenbaum and Jonathan Parker, eds., vol. 33, 307-372. Chicago: University of Chicago Press.

Chetty, Raj, Michael Stepner, Sarah Abraham, Shelby Lin, Benjamin Scuderi, Nicholas Turner, Augustin Bergeron, and David M. Cutler. 2016. "The Association Between Income and Life Expectancy in the United States, 2001-2014." JAMA 315(16): 1750-1766.

Chyn, Eric. 2018. "Moved to Opportunity: The Long-Run Effects of Public Housing Demolition on Children." American Economic Review 108(10): 3028-3056.

Chyn, Eric, and Lawrence F. Katz. 2021. "Neighborhoods Matter: Assessing the Evidence for Place Effects.” National Bureau of Economic Research Working Paper No. 28953.

Colmer, Jonathan, Ian Hardman, Jay Shimshack, and John Voorheis. 2020. "Disparities in PM2.5 Air Pollution in the United States." Science 369(6503): 575-578.

Currie, Janet, and Jonathan Gruber. 1996. "Saving Babies: The Efficacy and Cost of Recent Changes in the Medicaid Eligibility of Pregnant Women." Journal of Political Economy 104(6): 1263-1296.

Cutler, David M., Fabian Lange, Ellen Meara, Seth Richards-Shubik, and Christopher J. Ruhm. 2011. "Rising Educational Gradients in Mortality: The Role of Behavioral Risk Factors." Journal of Health Economics 30(6): 1174-87.

Cutler, David M., Ellen Meara, and Susan Stewart. 2020. "Socioeconomic Status and the Experience of Pain: An Example from Knees." National Bureau of Economic Research Working Paper No. 27974.

Deryugina, Tatyana, Garth Heutel, Nolan H. Miller, David Molitor, and Julian Reif. 2019. "The Mortality and Medical Costs of Air Pollution: Evidence from Changes in Wind Direction." American Economic Review 109(12): 4178-4219.

Deryugina, Tatyana, and David Molitor. 2020. "Does When You Die Depend on Where You Live? Evidence from Hurricane Katrina." American Economic Review 110(11): 3602-33.

Fenelon, Andrew, and Samuel H. Preston. 2012. "Estimating Smoking-Attributable Mortality in the United States." Demography 49(3): 797-818.

Finkelstein, Amy, Matthew Gentzkow, and Heidi L. Williams. 2019. "What Drives Prescription Opioid Abuse? Evidence from Migration." National Bureau of Economic Research 
Retirement and Disability Research Center NB19-02. Available at https://www.nber.org/ node/93438/center-papers/nb19-02.

Finkelstein, Amy, Matthew Gentzkow, and Heidi L. Williams. 2021. "Place-Based Drivers of Mortality: Evidence from Migration." American Economic Review 111(8): 2697-2735.

Friedson, Andrew I., Moyan Li, Katherine Meckel, Daniel I. Rees, and Daniel W. Sacks. 2021. "Cigarette Taxes, Smoking, and Health in the Long-Run." National Bureau of Economic Research Working Paper No. 29145.

Fuchs, Victor R. 1974. Who Shall Live? Health, Economics and Social Choice. New York: Basic Books.

Ganong, Peter, and Daniel Shoag. 2017. "Why Has Regional Income Convergence in the US Declined?" Journal of Urban Economics 102: 76-90.

Gaubert, Cecile, Patrick Kline, Damián Vergara, and Danny Yagan. 2021. "Trends in US Spatial Inequality: Concentrating Affluence and a Democratization of Poverty." National Bureau of Economic Research Working Paper No. 28385.

Gelman, Andrew. 2009. Red State, Blue State, Rich State, Poor State: Why Americans Vote the Way They Do (Expanded Edition). Princeton, NJ: Princeton University Press.

Glei, Dana A., and Samuel H. Preston. 2020. "Estimating the Impact of Drug Use on US Mortality, 1999-2016." PLoS One 15(1): e0226732.

Goodman-Bacon, Andrew. 2018. "Public Insurance and Mortality: Evidence from Medicaid Implementation." Journal of Political Economy 126(1): 216-262.

Goodman-Bacon, Andrew. 2021. "The Long-Run Effects of Childhood Insurance Coverage: Medicaid Implementation, Adult Health, and Labor Market Outcomes." American Economic Review 111(8): 2550-2593.

Grossman, Michael. 1972. "On the Concept of Health Capital and the Demand for Health." Journal of Political Economy 80(2): 223-255.

Harris, Kathleen Mullan, Steven H. Woolf, and Darrell J. Gaskin. 2021. "High and Rising Working-Age Mortality in the US: A Report From the National Academies of Sciences, Engineering, and Medicine." JAMA 325(20): 2045-2046.

Hollingsworth, Alex, Christopher J. Ruhm, and Kosali Simon. 2017. "Macroeconomic Conditions and Opioid Abuse." Journal of Health Economics 56: 222-233. 
Jokela, Markus. 2014. "Are Neighborhood Health Associations Causal? A 10-Year Prospective Cohort Study with Repeated Measurements." American Journal of Epidemiology 180(8): 776-784.

Kling, Jeffrey R., Jeffrey B. Liebman, and Lawrence F. Katz. 2007. "Experimental Analysis of Neighborhood Effects." Econometrica 75(1): 83-119.

Kochanek, Kenneth D., Sherry L. Murphy, Jiaquan Xu, and Elizabeth Arias. 2017. "Deaths: Final Data for 2017." National Vital Statistics Report 68(9). Hyattsville, MD: National Center for Health Statistics.

Kurle, Sydney. 2021. "The Silent Epidemic: Drug Overdose Deaths Surge in California Pre-pandemic." State of Reform, January 15. Available at https://stateofreform.com/featured/2021/01/the-silent-epidemic-drug-overdose-deathssurge-in-california-pre-pandemic/.

Ludwig, Jens, Greg J. Duncan, Lisa A. Gennetian, Lawrence F. Katz, Ronald C. Kessler, Jeffrey R. Kling, and Lisa Sanbonmatsu. 2012. "Neighborhood Effects on the Long-Term Well-Being of Low-Income Adults." Science 337(6101): 1505-1510.

McLafferty, Sara. 2020. "Place and Quantitative Methods: Critical Directions in Quantitative Approaches to Health and Place." Health and Place 61: 102232.

Meara, Ellen R., Seth Richards, and David M. Cutler. 2008. "The Gap Gets Bigger: Changes in Mortality and Life Expectancy, by Education, 1981-2000." Health Affiars 27(2): 350360 .

Miller, Sarah, Norman Johnson, and Laura R. Wherry. 2021. "Medicaid and Mortality: New Evidence from Linked Survey and Administrative Data." Quarterly Journal of Economics 136(3): 1783-1829.

Miller, Sarah, and Laura R. Wherry. 2019. "The Long-Term Effects of Early Life Medicaid Coverage." Journal of Human Resources 54(3): 785-824.

Montez, Jennifer K., Jason Beckfield, Julene K. Cooney, Jacob M. Grumbach, Mark D. Hayward, Huseyin Zeyd Koytak, Steven H. Woolf, and Anna Zajacova. 2020. "US State Policies, Politics, and Life Expectancy." The Milbank Quarterly 98(3): 668-699.

Montez, Jennifer K., and Lisa F. Berkman. 2014. "Trends in the Educational Gradient of Mortality among US Adults Aged 45 to 84 Years: Bringing Regional Context into the Explanation." American Journal of Public Health 104(1): e82-e90. 
Montez, Jennifer K., Anna Zajacova, Mark D. Hayward, Steven H. Woolf, Derek Chapman, and Jason Beckfield. 2019. "Educational Disparities in Adult Mortality Across US States: How Do They Differ, and Have They Changed Since the Mid-1980s?" Demography 56(2): 621-644.

Munson, Jeffrey, Nancy E. Morden, David C. Goodman, Luca F. Valle, and John E. Wennberg. 2013. The Dartmouth Atlas of Medicare Prescription Drug Use. Lebanon: NH: The Dartmouth Institute for Health Policy and Clinical Practice.

National Academies of Sciences, Engineering, and Medicine. 2021. High and Rising Mortality Rates Among Working-Age Adults. Washington, DC: The National Academies Press. Available at https://www.nap.edu/download/25976.

Novosad, Paul, Charlie Rafkin, and Sam Asher. 2020. "Mortality Change Among Less Educated Americans." Dartmouth College Department of Economics Working Paper. Available at https://paulnovosad.com/pdf/nra-mortality.pdf.

Pappas, Gregory, Susan Queen, Wilbur Hadden, and Gail Fisher. 1993. "The Increasing Disparity in Mortality between Socioeconomic Groups in the United States, 1960 and 1986." New England Journal of Medicine 329(2): 103-109.

Pierce, Justin R., and Peter K. Schott. 2016. "Trade Liberalization and Mortality: Evidence from US Counties." National Bureau of Economic Research Working Paper No. 22849.

Pierce, Justin R., and Peter K. Schott. 2020. "Trade Liberalization and Mortality: Evidence from US Counties." American Economic Review: Insights 2(1): 47-64.

Pinkovskiy, Maxim. 2019. "Does US Health Inequality Reflect Income Inequality — or Something Else?" Federal Reserve Bank of New York Liberty Street Economics, October 15. Available at https://libertystreeteconomics.newyorkfed.org/2019/10/does-us-healthinequality-reflect-income-inequalityor-something-else.html.

Preston, Samuel H., Yana C. Vierboom, and Andrew Stokes. 2018. "The Role of Obesity in Exceptionally Slow US Mortality Improvement." Proceedings of the National Academy of Sciences 115(5): 957-961.

Quinones, Sam. 2015. Dreamland: The True Tale of America's Opiate Epidemic. New York: Bloomsbury Press.

Ruhm, Christopher J. 2017. "Geographic Variation in Opioid and Heroin Involved Drug Poisoning Mortality Rates." American Journal of Preventive Medicine 53(6): 745-753. 
Ruhm, Christopher J. 2018. "Deaths of Despair or Drug Problems?" National Bureau of Economic Research Working Paper No. 24188.

Ruhm, Christopher J. 2019. "Drivers of the Fatal Drug Epidemic." Journal of Health Economics 64(March): 25-42.

Skinner, Jonathan, and Douglas Staiger. 2015. "Technology Diffusion and Productivity Growth in Health Care." Review of Economics and Statistics 97(5): 951-964.

Vierboom, Yana C., Samuel H. Preston, and Arun S. Hendi. 2019. "Rising Geographic Inequality in Mortality in the United States." SSM Population Health 9: 100478.

Woolf, Steven H., and Heidi Schoomaker. 2019. "Life Expectancy and Mortality Rates in the United States, 1959-2017." JAMA 322(20): 1996-2016. 


\section{Online Appendix for: "Rising Geographic Disparities in US Mortality"}

Benjamin K. Couillard Christopher L. Foote Kavish Gandhi Ellen Meara Jonathan Skinner

This version: September 21, 2021 


\section{Data Sources}

Replication files for this paper will be available at a web page maintained by the Journal of Economic Perspectives. All data are publicly available online, with the exception of the restricted-use mortality data from the National Vital Statistics System (NVSS). In this section, we outline our main data sources.

Mortality data: Mortality data are from NVSS's confidential microdata files for individual decedents (Centers for Disease Control and Prevention, National Center for Health Statistics 2017). These data can be accessed via application at https://www.cdc.gov/nchs/ nvss/nvss-restricted-data.htm. Where possible, results in the paper were validated using public-use data from the CDC Wonder Underlying Cause of Death Compressed Mortality Data, found at https://wonder.cdc.gov/mortSQL.html.

Life Expectancy: State-level life expectancy at birth is from the United States Mortality Database (2021). Data can be downloaded as .txt files after registering at https: //usa.mortality.org. National life expectancy rates through 2020 are from the National Center for Health Statistics and were retrieved using the Haver data service. The Haver mneumonics are USLE, USLEWX, USLEBX, USLEH, USLEB, USLEW in the USECON database.

Population: Population estimates used in the denominators of mortality-rate estimates are from National Cancer Institute's Surveillance, Epidemiology, and End Results Program (SEER). Breakdowns into state-education cells were estimated using Current Population Survey microdata from IPUMS (Flood et al. 2020). The SEER data can be downloaded from https://seer.cancer.gov/popdata/download.html, and the IPUMS-CPS data are available at https://cps.ipums.org/cps/. State-level population estimates through 2020, used in the population-weighting of Figure 1, are from the US Census Bureau's Resident Population Annual Estimates program and can be downloaded from the Federal Reserve Bank of St. Louis at https://fred.stlouisfed.org/release/tables?rid=118\&eid=259194.

State-level Covariates: Our exploratory regressions are discussed near the end of the main text and outlined in more detail in Section 4 of this appendix. The state-level covariates used in these regressions include:

- Income: The per capita income variable used in the exploratory regressions is the same income variable used throughout the main text. Real per capita personal income is based on estimates from the Bureau of Economic Analysis (BEA) of total personal income received by the residents of individual states in each year. These data can be downloaded from BEA's Regional Data Tables (Table SAINC1) at https: //apps.bea.gov/itable/iTable.cfm?ReqID $=70 \&$ step $=1$. In addition to total personal income by state, this table also includes per capita personal income, defined by BEA 
as total personal income divided by state population as of July 1 of the given year. We express that per capita figure in 2012 dollars using BEA's price deflator for personal consumption expenditures, which can be downloaded from the St. Louis Fed at https://fred.stlouisfed.org/series/PCEPI.

- Smoking and obesity: State-level smoking and obesity data come from the Behavioral Risk Factor Surveillance System (BRFSS), an annual set of telephone surveys conducted by the Centers for Disease Control and Prevention (2021). We use BRFSS's post-stratification weights to construct state-level shares of daily smokers and to calculate obesity rates. Daily smokers are defined as respondents who report smoking every day and having smoked at least 100 cigarettes throughout their lifetimes. Obesity is defined as having a body mass index greater than 30.0. ${ }^{1}$ BRFSS data are downloadable from https://www.cdc.gov/brfss/annual_data/annual_data.htm.

- College shares: State-level college shares are estimated separately from CPS data and from the Census and ACS Educational Attainment tables. The data for 1940 through 2000 are downloadable from https://www.census.gov/data/tables/2000/dec/phc-t-41. html. For 2010 through 2018, the data are in Table S1501 at the Census website (https://data.census.gov/cedsci/table?q=S1501\&tid=ACSST1Y2019.S1501).

- Poverty: State-level poverty rates from 1980 through 2019 are from the Census Bureau's Historical Poverty Tables and are based on the CPS's Annual Social and Economic Supplements (ASEC, also known as the March CPS). The data are at https:// www.census.gov/data/tables/time-series/demo/income-poverty/historical-poverty-people. html.

- Manufacturing shares: Yearly manufacturing shares are drawn from the BEA's estimates of employment by state and industry from 1969 through 2018 (Table SAEMP25), which can be downloaded from BEA's Regional Data Tables web page (https://apps. bea.gov/itable/iTable.cfm?ReqID=70\&step=1). The manufacturing share is defined as the percentage share of nonfarm employment, where employment is classified by the Standard Industrial Classification System (SIC) through 1997 and the North American Industrial Classification System (NAICS) after 1997.

- Prescription quality: Data from the Dartmouth Atlas of Medicare Prescription Drug Use (Munson et al. 2013) are used to measure prescribing quality based on 2008-2010 data for Medicare enrollees aged 65 and older. We include an index of both highquality prescribing (for example, prescriptions for beta blockers and statins in the

\footnotetext{
${ }^{1}$ Body mass index is defined as (weight in kilograms) $\div$ (height in meters). ${ }^{2}$
} 
first six months following a heart attack) and poor-quality prescribing (for example, prescriptions for high-risk medications for which clinical risks exceed benefits, such as muscle relaxants for frail elderly patients). The Dartmouth data reference only the years 2008 through 2010.

\section{Life Expectancy and Mortality by Race/Ethnicity}

Figure A.1 parallels Figure 1 of the main text, which shows that national life expectancy was essentially flat after 2010 and fell slightly after 2014. Figure A.1 shows that this general pattern is also found among individual racial and ethnic groups.

Figure A.2 parallels Figure 6 of the main text, which documents rising state-level dispersion in both all-cause mortality and in deaths of despair. The appendix figure shows that white non-Hispanic and Black populations also display increasing state-level dispersion; by contrast, such dispersion decreases in the Hispanic population. This pattern demonstrates that racial patterns alone do not explain the results in Figure 6, while also illustrating some relevant intra-group dynamics in mortality that are beyond the scope of our paper.

\section{Decomposition of State-Level Mortality Dispersion}

Figure 4 in the main text is a decomposition of dispersion in log state-level mortality rates since 1992. The underlying model for this decomposition starts by noting that the mortality rate for persons aged 25 to 64 in state $i$ and year $t, m_{i t}$, can be written as the weighted average of education-specific mortality rates:

$$
m_{i t}=s_{i t}^{C} m_{i t}^{C}+s_{i t}^{N} m_{i t}^{N},
$$

where $s_{i t}^{C}$ is the population share of college-educated adults among the state's 25- to 64year-olds, $s_{i t}^{N}=1-s_{i t}^{C}$ is the non-college population share, and $m_{i t}^{C}$ and $m_{i t}^{N}$ are the midlife mortality rates for the state's college and non-college populations, respectively. The individual mortality rates for the two education groups can be modelled in log form as

$$
\begin{aligned}
& \ln \left(m_{i t}^{C}\right)=\mu_{t}+\epsilon_{i t}^{C} \\
& \ln \left(m_{i t}^{N}\right)=\mu_{t}+\lambda_{t}+\epsilon_{i t}^{N} .
\end{aligned}
$$

In this system, the average mortality rate for college-educated Americans in year $t$ is denoted by $\mu_{t}$, while $\lambda_{t}$ reflects a national non-college mortality "penalty," which is well known to have been rising since the early 1990s. The notation implies that the national non-college 
rate in year $t$ is $\mu_{t}+\lambda_{t}$. Consequently, the residuals $\epsilon_{i t}^{C}$ and $\epsilon_{i t}^{N}$ denote deviations from education-specific national rates in the given state and year.

As noted in the text, this structure allows us to decompose the sources of rising geographic disparities in mortality into four channels: (a) state-level changes over time in college shares $s_{i t}^{C}$, whether because of higher educational attainment within the state or because of migration; (b) a widening of the national non-college mortality penalty $\lambda_{t}$, which will benefit states with high (or increasing) shares of college graduates; (c) an increase in the standard deviation of the state-year college residuals $\epsilon_{i t}^{C}$; and (d) an increase in the standard deviation of residuals for non-college residents $\epsilon_{i t}^{N}$. Because our ultimate objective is to explain rising dispersion in $\log$ state-level mortality rates, changes in the national college effect $\mu_{t}$ do not matter, because this term affects (the log of) college and non-college mortality rates equally.

In the text, we use a series of counterfactual experiments to explore the relative contributions of these four channels to rising dispersion in state-level mortality. These experiments start by holding all model elements constant at their 1992 values. We then replace those baseline values with actual values of model elements in a series of steps, starting with actual college and non-college shares $s_{i t}^{C}$ and $s_{i t}^{N}$. Using actual shares changes the implied values of $m_{i t}$ due to the presence of these shares in equation (1). Additional counterfactuals use actual values of $\lambda_{t}, \epsilon_{i t}^{C}$, and $\epsilon_{i t}^{N}$, which change the implied state-level mortality rates via their presence in the two-equation system (2). When actual values of the latter three elements are used, we exponentiate the new log mortality rates and then feed the resulting rates into equation (1), which generates a new set of state-specific mortality rates $m_{i t}$. In all of the counterfactuals, we take logs of the implied $m_{i t}$ s before figuring the standard deviation, because Figure 4 depicts the standard deviation of log state-level mortality rates.

As noted in the main text, adding actual college and non-college shares $s_{i t}^{C}$ and $s_{i t}^{N}$ has only a modest impact on the standard deviation of state-level mortality, while the widening national college differential $\lambda_{t}$ adds a bit more. Rising variation in the college residuals $\epsilon_{i t}^{C}$ adds an additional amount of dispersion, but most of the increase in dispersion in state-level mortality over time is explained by a fanning out of the non-college residuals $\epsilon_{i t}^{N}$.

Our series of counterfactuals is not a formal variance decomposition, which would require us to account for changing covariances among the various model elements. One disadvantage of our simpler approach is that the results of the exercise depend on the order in which actual model elements are introduced. In Figure A.3, however, we show that different orderings of the decomposition do not change our bottom line: Rising dispersion is caused largely by rising variance in the residual elements $\epsilon_{i t}^{C}$ and $\epsilon_{i t}^{N}$, not by changing college shares or the rising educational penalty $\lambda_{t}$.

The model above can be modified to analyze the importance of state-wide "place effects," if we are willing to assume a specific way in which place effects manifest themselves. For 
example, if place effects have equal effects on mortality among the state's college and noncollege populations, then we can replace the two-equation system (2) with

$$
\begin{aligned}
& \ln \left(m_{i t}^{C}\right)=\phi_{i t}+u_{i t}^{C} \\
& \ln \left(m_{i t}^{N}\right)=\phi_{i t}+\lambda_{t}+u_{i t}^{N} .
\end{aligned}
$$

In the new system, the place effect $\phi_{i t}$ captures "average" mortality in the state, once the national non-college penalty $\lambda_{t}$ has been accounted for. Conceptually, this place effect reflects the equally weighted average of the residuals $\epsilon_{i t}^{C}$ and $\epsilon_{i t}^{N}$ from the earlier two-equation system $(2) .^{2}$ Because our place effect $\phi_{i t}$ reflects average mortality, the residuals in the new system, $u_{i t}^{C}$ and $u_{i t}^{N}$, must sum to zero and are therefore equal in absolute value and of opposite sign.

We can use the new system to construct a series of counterfactuals similar to those that appear in the main text. The main objective now is to see how much the new place effect $\phi_{i t}$ matters for the widening dispersion of state-level log mortality rates. Results of this exercise appear in Figure A.4. As before, using actual college shares has little effect on statelevel dispersion, and changes in the national education penalty $\lambda_{t}$ also have a limited effect. Including actual values of place effects $\phi_{i t}$, however, matters a great deal. Our estimated place effect relies on the equal-weight assumption, and the results in the text (as well as previous research) indicate that place effects could well be stronger at the lower end of the income or educational distribution. Even so, we view these additional results as evidence that place effects with wide-ranging effects throughout a state could be an important driver of increased mortality dispersion over time.

Finally, note that our decomposition in (1) is only approximate due to the age-adjustment of the mortality rates. In practice, this means that the college shares used in the decomposition exercise in the main text are not exactly equal to actual college shares. However, we can verify the thrust of our main results with counterfactuals that use crude mortality rates, which allow for a decomposition with exact college shares. Figure A.5 shows a robustness check using the model with separate college and non-college residuals, while Figure A.6 depicts the robustness check using crude rates for the combined place-effect model.

\section{Exploratory Regressions}

The main text discusses some exploratory regressions that project the log of state-level overall mortality rates on various state-level explanatory variables, including real per capita personal income, the poverty rate, the manufacturing employment share, the smoking and obesity rates, and pharmaceutical-prescription quality. Results of these regressions are shown

\footnotetext{
${ }^{2}$ Rather than using equal weights, an alternative method would define $\phi_{i t}$ as an average that uses the national share of college and non-college graduates over the time period considered.
} 
in Table A.1. Each column of the table depicts a regression of log mortality from a single year: 1992, 2000, or 2016. The right-hand-side variables are dated as of the same year, except the prescription-quality variables, which reference only the years 2008 through 2010. The table has two major takeaways. First, comparing columns (1), (3), and (5) demonstrates the increasing importance of income over time. A significantly negative income coefficient appears by 2000, and this coefficient becomes even more negative in 2016. Second, comparing columns (2), (4), and (6) shows that when other variables besides income are included, the negative effect of state-level income is reduced. This reduction indicates that high-income states differ from low-income states along a variety of dimensions relevant for health, which are being captured in some ways by these additional variables. 


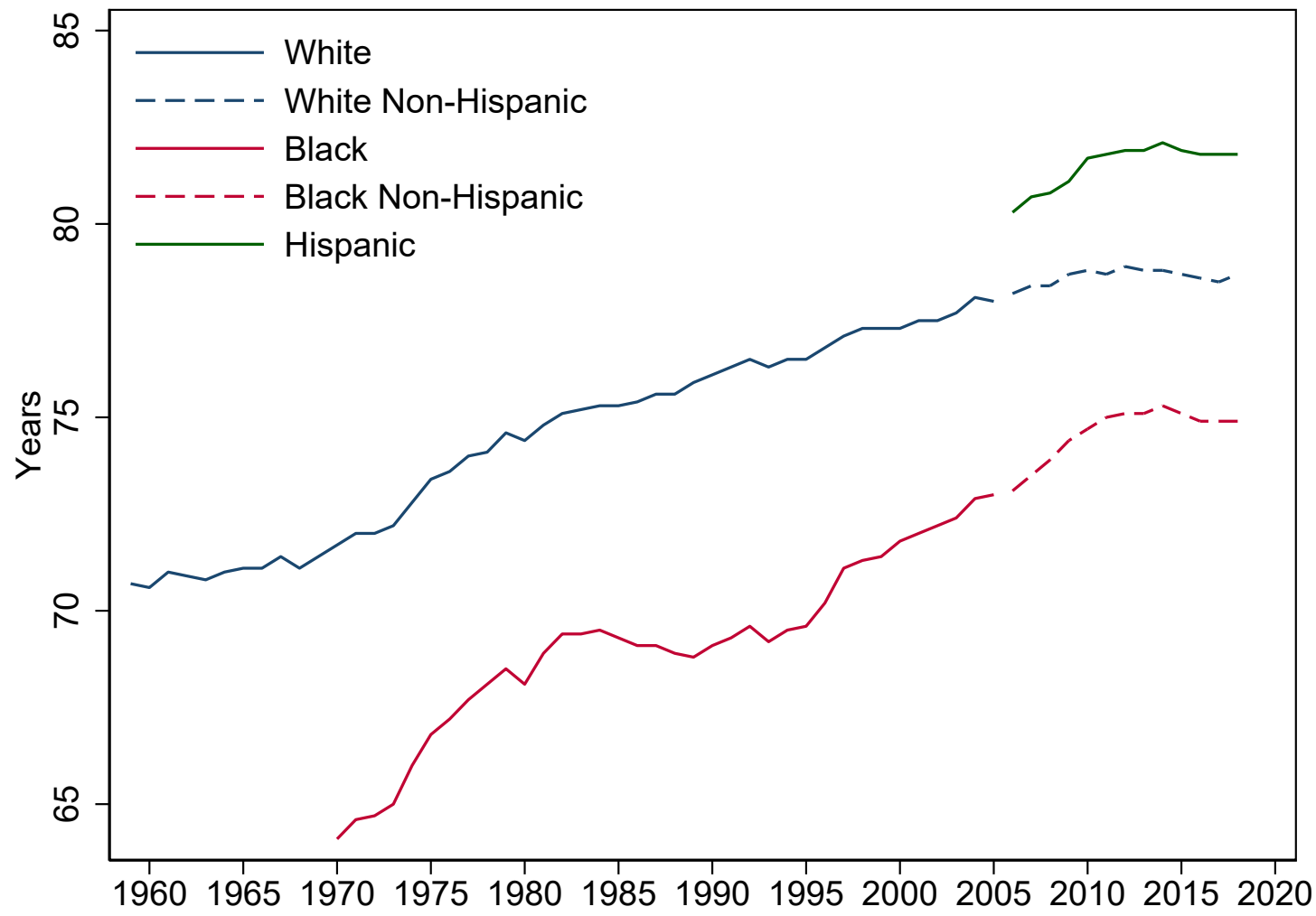

Figure A.1. US Life Expectancy at Birth by Race/Ethnicity. 

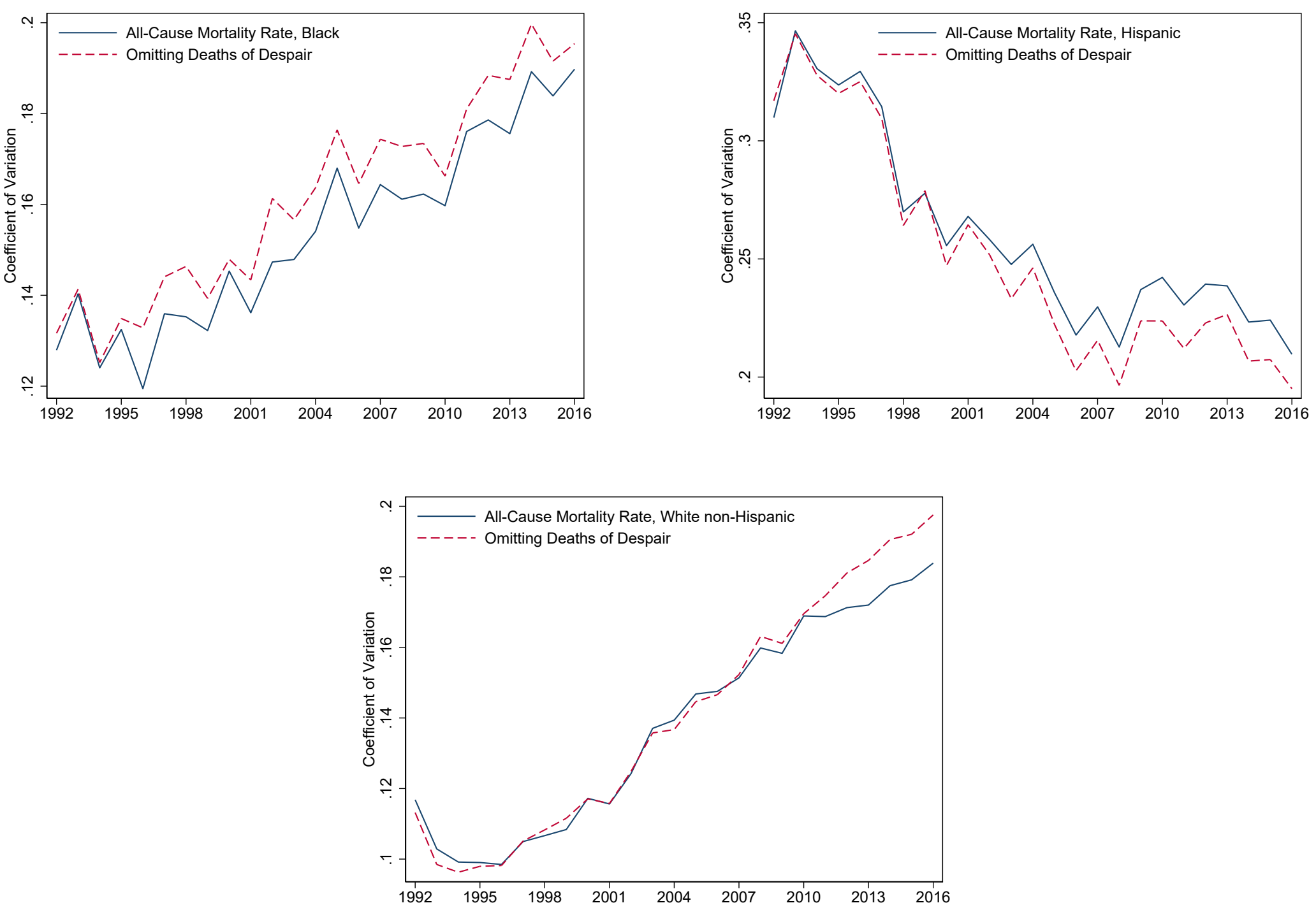

Figure A.2. Coefficients of Variation for All-Cause Mortality and Mortality Omitting Deaths of Despair, by Race/Ethnicity. Note: This figure shows that state-level dispersion in mortality rises over time among Black and white non-Hispanic populations, while mortality dispersion declines in the Hispanic population. Mortality rates are age adjusted and correspond to persons aged 25 to 64 . Deaths of despair are deaths attributed to poisonings, suicide, or cirrhosis (ICD9: 571, E950-959, E850-860 and E980-982; ICD10: K70 and K73-74, X60-84 and Y87.0, X40-X45 and Y10-15). Coefficients of variation are population weighted. 

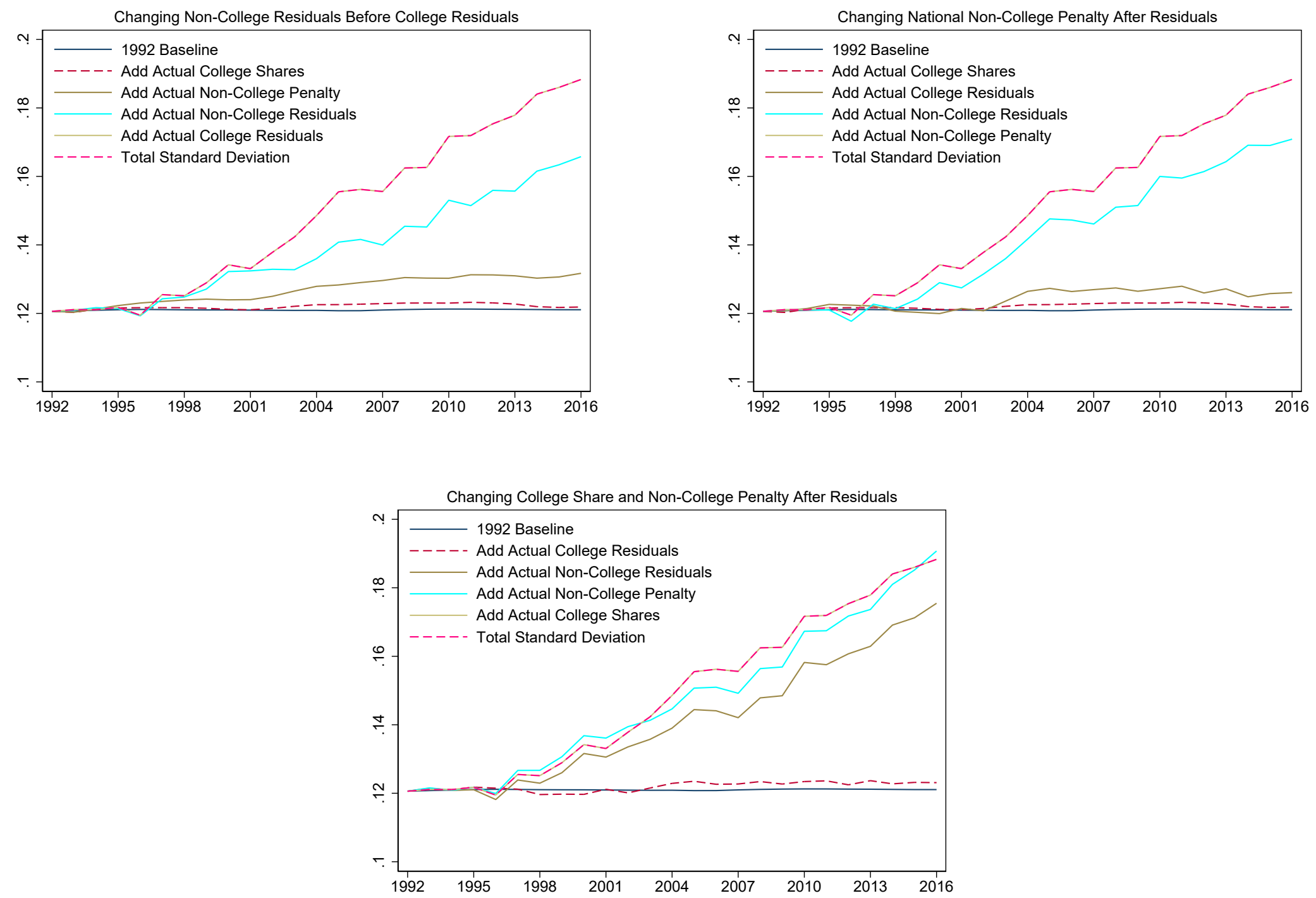

Figure A.3. Changing the Order of Model Elements in the Decomposition of Mortality Dispersion. Note: Each panel displays standard deviations for a series of counterfactual sets of log state-level mortality rates, which are built up using the statistical framework outlined in section 3 of this appendix and discussed more briefly in the main text. The panels are distinguished by the order in which actual values of model elements are incorporated into the statistical framework. Across all panels, rising state-level dispersion is driven largely by rising dispersion in college and non-college residuals, not by changing college shares or the rising non-college mortality penalty. 

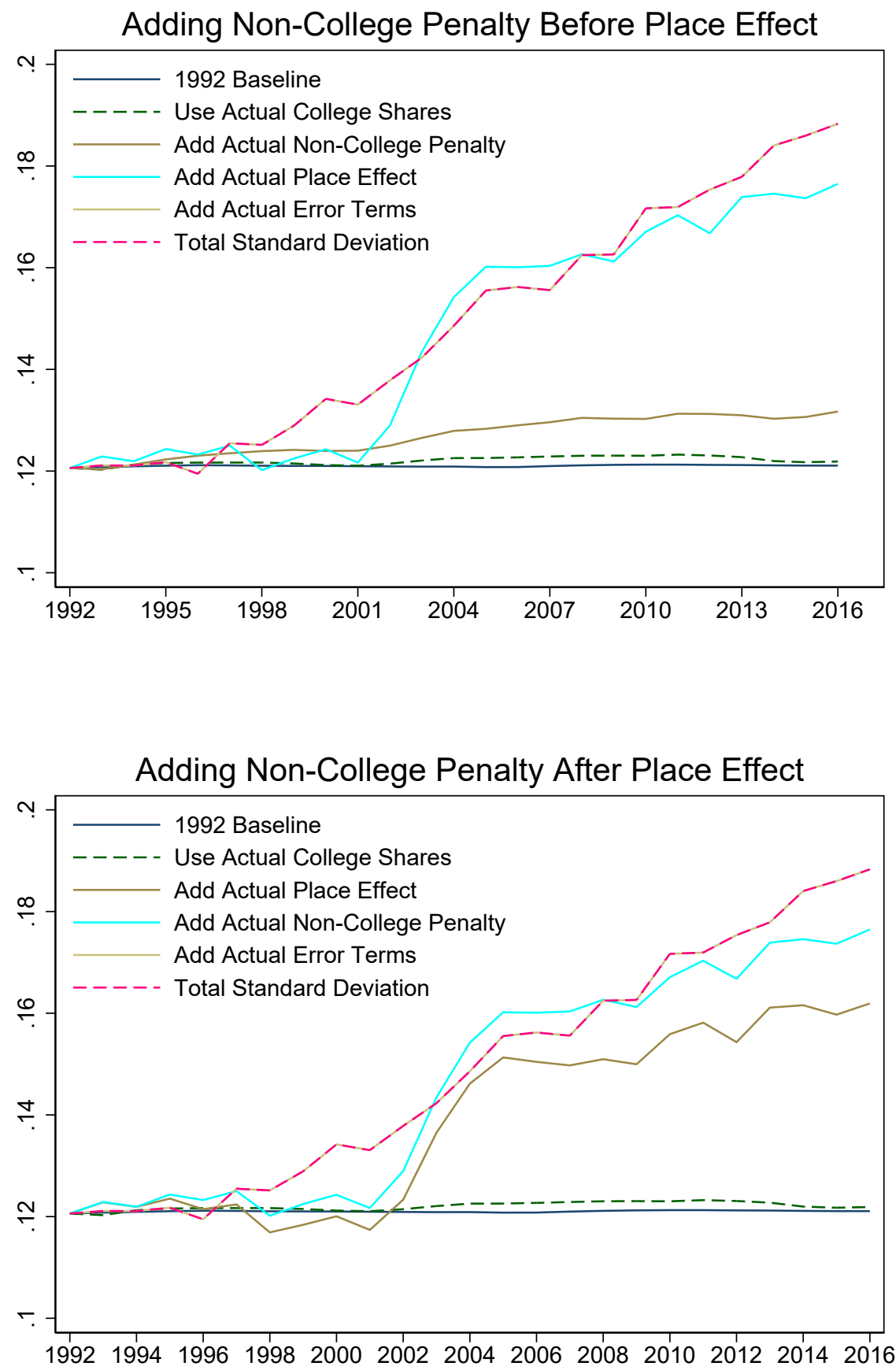

Figure A.4. Counterfactual Exercise in Place-Effect Model. Note: Each panel displays standard deviations for a series of counterfactual sets of log state-level mortality rates, built up using the "place effect" model outlined in section 3 of this appendix. In this model, the noncollege and college residuals of the basic model are essentially collapsed into a single place effect that is shared by both educational groups. The figure confirms that rising dispersion in log state-level mortality rates is driven largely by the rising dispersion in place effects, regardless of the order in which actual model elements are incorporated into the statistical framework. 
Identical Order as in Figure 4, Crude Mortality Rates

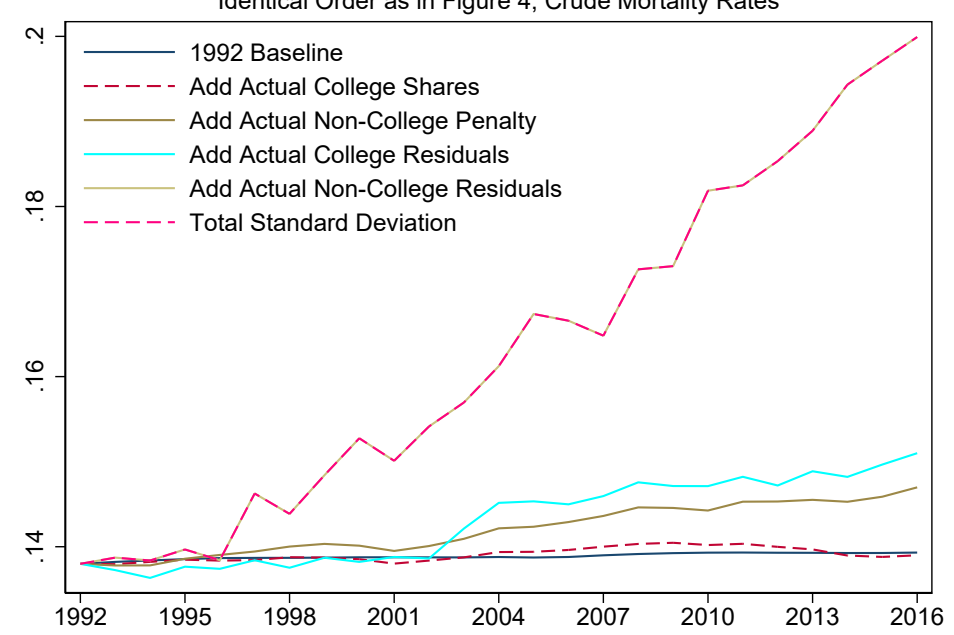

$\stackrel{P}{\stackrel{D}{上}}$

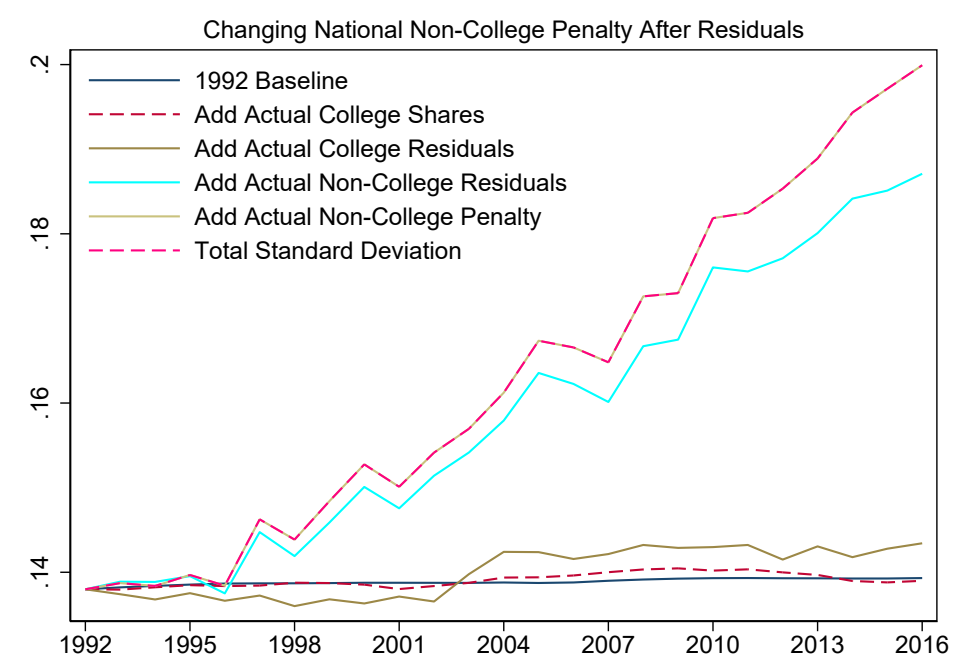

Changing Non-College Residuals Before College Residuals
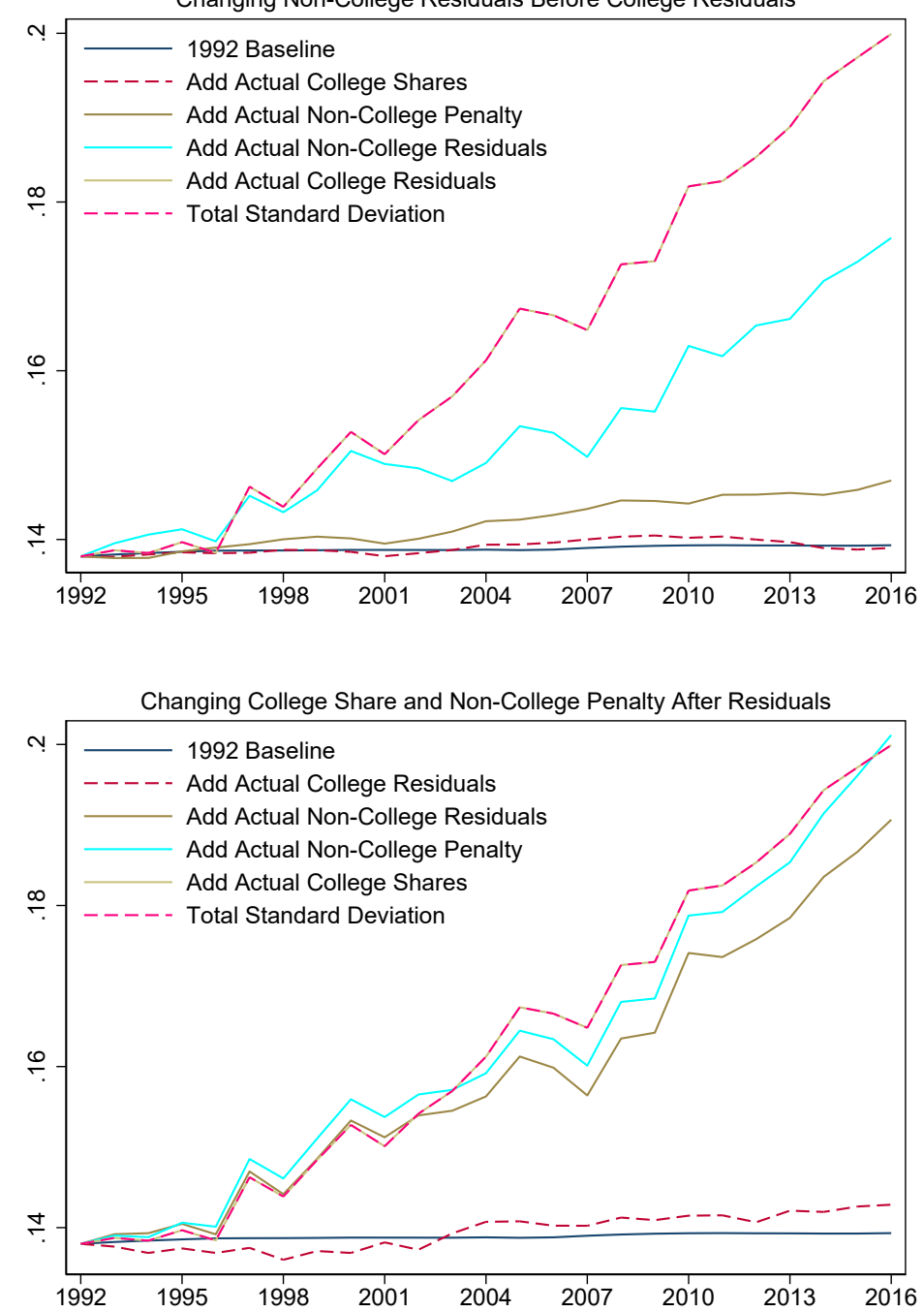

Figure A.5. Decomposition using Crude Rather than Age-Adjusted Mortality Rates Note: Each panel displays standard deviations for a series of counterfactual sets of log state-level mortality rates. All panels use crude rather than age-adjusted mortality data (the decomposition is exact only with crude mortality rates). The figure confirms that even with crude rates, rising state-level dispersion is driven largely by rising variance in the college and non-college residuals. This fact remains true regardless of the order in which actual model elements are incorporated into the statistical framework. 

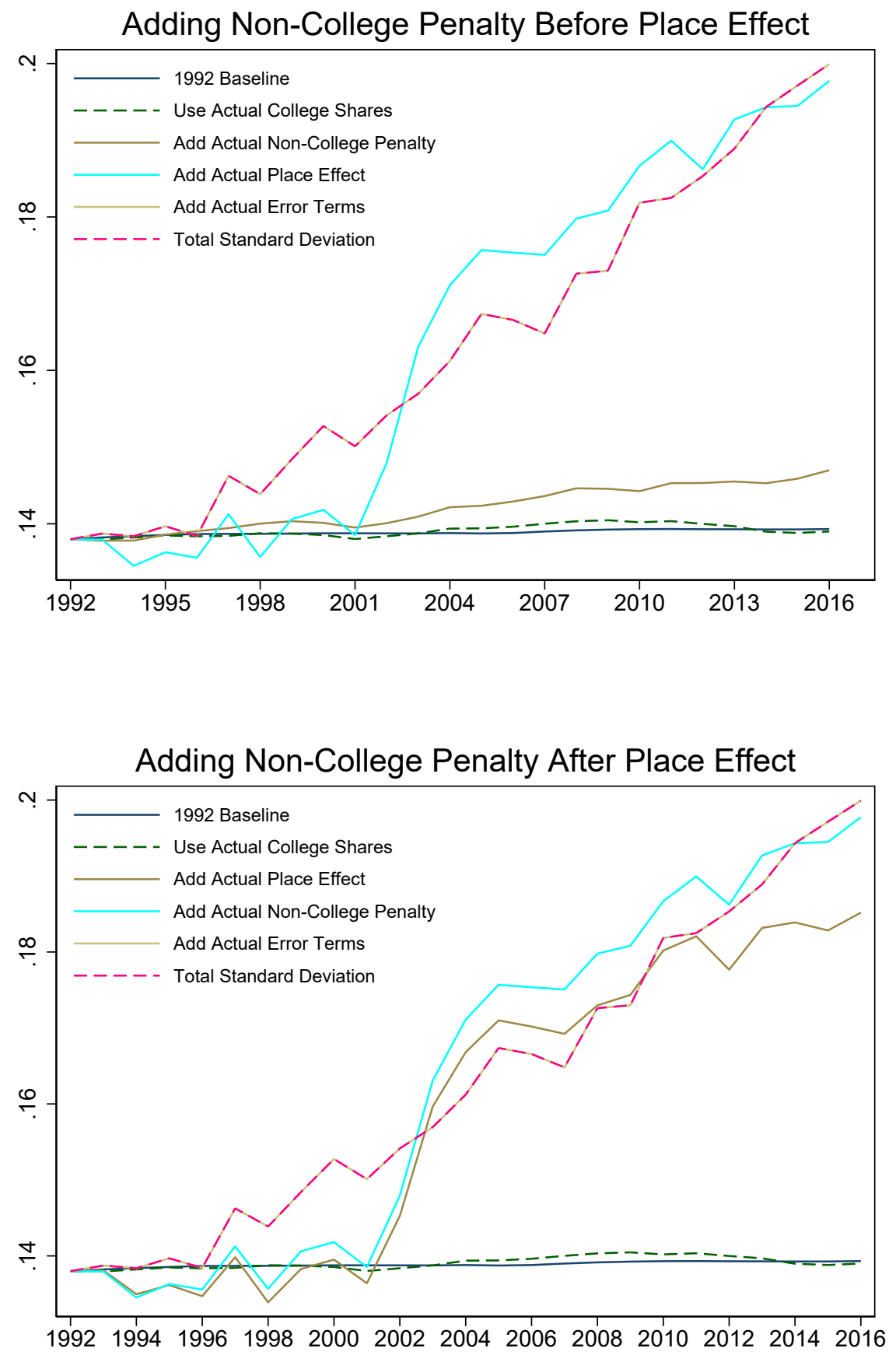

Figure A.6. Counterfactual Exercise in Place-Effect Model Using Crude Mortality. Note: These panels show a robustness check for the counterfactual exercise that uses crude mortality rates. (See Figure A.4 for the place effect model using age-adjusted rates.) The panels show that the approximate nature of the decomposition when using age-adjusted mortality rates is not driving our results in the place effect model. 


\begin{tabular}{|c|c|c|c|c|c|c|}
\hline Year & $\begin{array}{c}(1) \\
1992\end{array}$ & $\begin{array}{c}(2) \\
1992\end{array}$ & $\begin{array}{c}(3) \\
2000\end{array}$ & $\begin{array}{c}(4) \\
2000\end{array}$ & $\begin{array}{c}(5) \\
2016\end{array}$ & $\begin{array}{c}(6) \\
2016\end{array}$ \\
\hline $\begin{array}{l}\text { Log of Real Per Capita } \\
\quad \text { Personal Income }(\$ 2012)\end{array}$ & $\begin{array}{l}-0.173 \\
(0.180)\end{array}$ & $\begin{array}{c}0.527^{* * *} \\
(0.124)\end{array}$ & $\begin{array}{c}-0.466^{* *} \\
(0.141)\end{array}$ & $\begin{array}{l}0.304^{* * *} \\
(0.0859)\end{array}$ & $\begin{array}{c}-0.977^{* * *} \\
(0.131)\end{array}$ & $\begin{array}{l}-0.260^{*} \\
(0.113)\end{array}$ \\
\hline Poverty Share & & $\begin{array}{l}0.0182^{* * *} \\
(0.00496)\end{array}$ & & $\begin{array}{c}0.0103 \\
(0.00528)\end{array}$ & & $\begin{array}{c}0.00626 \\
(0.00904)\end{array}$ \\
\hline Smoking Rate & & $\begin{array}{l}1.062^{*} \\
(0.520)\end{array}$ & & $\begin{array}{l}1.346^{* *} \\
(0.462)\end{array}$ & & $\begin{array}{c}2.885^{* * *} \\
(0.492)\end{array}$ \\
\hline Obesity Rate & & $\begin{array}{c}0.536 \\
(0.966)\end{array}$ & & $\begin{array}{c}0.824 \\
(1.103)\end{array}$ & & $\begin{array}{c}0.185 \\
(0.761)\end{array}$ \\
\hline Manufacturing Share & & $\begin{array}{l}-0.355 \\
(0.267)\end{array}$ & & $\begin{array}{l}-0.574 \\
(0.389)\end{array}$ & & $\begin{array}{l}-1.081 \\
(0.549)\end{array}$ \\
\hline $\begin{array}{l}\text { Good-Prescription } \\
\text { Rate }\end{array}$ & & $\begin{array}{l}-0.00422 \\
(0.00885)\end{array}$ & & $\begin{array}{c}-0.0116 \\
(0.00867)\end{array}$ & & $\begin{array}{l}-0.00933 \\
(0.00656)\end{array}$ \\
\hline $\begin{array}{l}\text { Risky-Prescription } \\
\text { Rate }\end{array}$ & & $\begin{array}{c}0.0120^{* *} \\
(0.00364) \\
\end{array}$ & & $\begin{array}{l}0.0172^{* * *} \\
(0.00371) \\
\end{array}$ & & $\begin{array}{l}0.0107^{* *} \\
(0.00340)\end{array}$ \\
\hline R-squared & 0.025 & 0.790 & 0.202 & 0.815 & 0.578 & 0.893 \\
\hline$N$ & 44 & 44 & 44 & 44 & 44 & 44 \\
\hline
\end{tabular}

Table A.1. State-Level Regressions of Log Age-Adjusted Midlife Mortality Rates in Selected Years. Note: Standard errors in parentheses. ${ }^{*} p<0.05,{ }^{* *} p<0.01,{ }^{* * *} p<0.001$. Comparing columns (1), (3), and (5) demonstrates the increasing correlation of mortality rates with income over time. However, columns (2), (4) and (6) show that income is likely standing in for other effects, as the income coefficient is made significantly less negative after adding additional behavioral, labor market, and healthcare-quality variables. Also note the rising correlation of the smoking rate with mortality; this pattern suggests that smoking could be a "sentinel" measure reflecting changes in both behavior and state-level policies. The number of observations is fewer than 50 due to limited data availability of some covariates. 


\section{Appendix References}

Centers for Disease Control and Prevention (CDC). 2021. "Behavioral Risk Factor Surveillance System (BRFSS)." US Department of Health and Human Services, Centers for Disease Control and Prevention.

Centers for Disease Control and Prevention, National Center for Health Statistics. 2017. "Restricted-Use Vital Statistics Data 1989-2017." Data are as compiled from data provided by the 57 vital statistics jurisdictions through the Vital Statistics Cooperative Program.

Flood, Sarah, Miriam King, Renae Rodgers, Steven Ruggles, and J. Robert Warren. 2020. "Integrated Public Use Microdata Series (IPUMS), Current Population Survey: Version 8.0 Basic Monthly."

Munson, Jeffrey, Nancy E. Morden, David C. Goodman, Luca F. Valle, and John E. Wennberg. 2013. The Dartmouth Atlas of Medicare Prescription Drug Use. Lebanon: NH: The Dartmouth Institute for Health Policy and Clinical Practice.

United States Mortality Database. 2021. University of California, Berkeley. Available at www.mortality.org. 